\title{
Blockchain drivers to achieve sustainable food security in the Indian context
}

\author{
Vinay Surendra Yadav ${ }^{1} \cdot$ A. R. Singh ${ }^{1} \cdot$ Rakesh D. Raut $^{2} \cdot$ Naoufel Cheikhrouhou $^{3}$
}

Accepted: 28 September 2021

(c) The Author(s) 2021

\begin{abstract}
Blockchain has the potential to improve sustainable food security due to its unique features like traceability, decentralized and immutable database, and smart contract mechanisms. However, blockchain technology is still in the early stages of adoption in particular in agricultural applications. In this context, this article aims to identify blockchain drivers to achieve sustainable food security in the Indian context and model them using an integrated MCDM (Multiple Criteria Decision Making) approach. The blockchain adoption drivers are identified through an exhaustive literature review and opinions from domain experts from industry, academia, and Agriculture Supply Chain (ASC) stakeholders. Subsequently, the integrated MCDM approach is developed by combining Total Interpretive Structural Modelling (TISM) and Fuzzy Decision-Making Trial and Evaluation Laboratory (DEMATEL), which does not only investigate the interrelation between the identified constructs and builds hierarchy but also determines the intensity of the causal interrelationships. At a later stage, Fuzzy CrossImpact Matrix Multiplication Applied to Classification (MICMAC) is used to cluster the identified drivers to evaluate the importance of each driver. The results reveal that Traceability, Real-time information availability to agro-stakeholder, and Decentralized and immutable database are the most significant drivers. Policymakers, governmental organizations and other relevant stakeholders may utilize the information about the interrelationship between these drivers and their influential power, to frame suitable strategies for enhancing the adoption rate of blockchain in the Indian ASC.
\end{abstract}

$凶 \quad$ Naoufel Cheikhrouhou

naoufel.cheikhrouhou@hesge.ch

Vinay Surendra Yadav

vinaysyadav93@gmail.com

A. R. Singh

arsingh.mech@nitrr.ac.in

Rakesh D. Raut

rraut@nitie.ac.in

1 National Institute of Technology, Raipur, India

2 National Institute of Industrial Engineering (NITIE), NITIE, Vihar Lake, Powai, Mumbai, Maharashtra, India 400087

3 Geneva School of Business Administration, University of Applied Sciences Western Switzerland, HES-SO, 1227 Carouge, Switzerland 
Keywords Blockchain · Agriculture Supply Chain · Sustainable Food Security · Total Interpretive Structural Modelling · Fuzzy MICMAC · Fuzzy DEMATEL

\section{Introduction}

According to the Food and Agriculture Organization of the United Nations (FAO, 1996), "a sustainable food system supports food security, makes optimal use of natural and human resources, is culturally acceptable and accessible, environmentally sound and economically fair and viable, and provides the consumer with nutritionally adequate, safe, healthy and affordable food for present and future generations." Such a sustainable food supply chain could be achieved through tracking agricultural practices and efficient food distribution networks, thus enabling and ensuring sustainable food security. In the Indian context, both state and central governments jointly ensure food security through a combination of various schemes. For this, India's Government has established a considerable network in the form of a "Public Distribution System (PDS)." The PDS's responsibility is to ensure the distribution of essential food items to millions of people living below the poverty line (George, 1999). However, there are many obstacles like adulteration of food, food fraud and inferior quality of food, which results in the failure of the PDS's primary purpose of ensuring food safety and nutritive value (Dev \& Sharma, 2010).

Moreover, the Indian ASC is disorganized, complicated, disintegrated, and involves many intermediaries (Vishwadham \& Kameshwaran, 2013), which results in inefficient agribusiness. Combining these factors and socio-economic conditions and demand (due to the large Indian population) makes it more challenging to ensure food security. Another challenge is to ensure food safety and sustainability. Furthermore, Indian food security programs face strategic challenges in procurement, finance, storage, production, transportation, distribution, and organization (Mahapatra \& Mohanty, 2018). Thus to enable sustainable food security, technology integration is necessary (Klerkx \& Rose, 2020; Mahapatra \& Mohanty, 2018). Blockchain Technology (BT) is one such technology that could help to achieve sustainable food security due to its unique features like decentralized and immutable databases, peer to peer (P2P) network, distributed and synchronized across networks and smart contract mechanisms (Cole et al., 2019).

Blockchain is a "shared, cryptographically unaltered distributed ledger" to record and maintain the digital transaction history. Each node/party connected to the blockchain system stores a copy of all previous records/transactions ever carried out on the concerned system. Furthermore, it is a decentralized system, which means that no single party is the owner and each transaction on the blockchain system is auditable and visible to all connected nodes (Clohessy \& Acton, 2019). Thus, a blockchain-based system would create a foundation of trust for businesses (Li et al., 2018; Sharma et al., 2019). All transaction carried out in blockchain-based system follows various consensus algorithms like "Proof of Work (PoW), Practical Byzantine Fault Tolerance (PBFT), Proof of Stake (PoS), Proof of Capacity; Proof of Burn (PoB) and Proof of Elapsed Time", etc. These consensus mechanisms are beneficial and ensure complete validation and authorization of transactions carried out in the network. In addition, the blockchain-based system does not require public and private institution intermediaries, thus reducing the transaction cost by a significant margin.

Blockchain enables traceability in the ASC while smart contracts facilitate the agribusiness in a smooth form. In addition, the Blockchain-based system brings sustainability to SC operations (Saberi et al., 2019). Blockchain seems to have great potential in bringing 
significant reformation in the ASC, but its adoption in actual practice is still in the early stages (Ge et al., 2017; Zhao et al., 2019). India being a developing nation, might unleash blockchain potential to meet its consumers' growing demands and needs. There are indeed several attempts to use blockchain in activities related to agriculture; The Indian state Andhra Pradesh uses blockchain for land registration and recording sales transactions in new capital Amravati (Bhattacharya, 2018). Blockchain could also act as a settlement platform in ASC with the help of smart contracts because of the decentralized and immutable nature of the database. The Indian state, Kerala, in conjunction with the Indian Institute of Information Technology and Management has established the 'blockchain academy' to train and impart blockchain learning to leverage full potential. According to (NASSCOM, 2019), India was expected to develop the biggest market for blockchain in 2020, where the States of Andhra Pradesh and Telangana are the two frontier states of blockchain adoption.

However, there is still a little knowledge of the drivers of blockchain adoption in Agriculture Supply Chains. Thus, this study targets the following research questions:

RQ1: What are the drivers for the adoption of blockchain to enable sustainable food security in the Indian ASC context?

RQ2: What kind of interrelationship exists between these drivers?

RQ3: What is the intensity of these interrelationships?

To address these questions, the following research objectives are framed:

RO1: To identify the drivers for the adoption of blockchain to achieve sustainable food security in the Indian ASC context.

RO2: To model these drivers for investigating interrelationships and building their hierarchy.

RO3: To evaluate the intensity of causal interrelationships amongst identified constructs and cluster them in suitable categories.

The next section presents the relevant literature about the recent development in ASC, sustainable food security, and blockchain adoption in ASC. The research methodology utilized for the current study is depicted in Sect. 3, while Sect. 4 emphasizes the application of the proposed methodology and data used for the same. The results are presented and discussed in Sect. 5, along with the managerial implication of the study. Finally, the concluding remarks are present in Sect. 6.

\section{Literature review}

Food security "exists when all people, at all times, have physical and economic access to sufficient, safe and nutritious food to meet their dietary needs and food preferences for an active and healthy life" (FAO, 1996). However, according to the World Hunger Statistics, 795 million people do not have sufficient food to live a healthy life. Thus, it is prevalent to say that ensuring sustainable food security is a significant concern for governments across the globe. This problem has further intensified due to increased population, urbanization, and climatic change leading to a loss of food production (Campbell et al., 2016). In addition, there exist several other risks and their impact on the performance of retail FSC could be referred in the work of Srivastava et al. (2015). Moreover, food fraud and food waste in the ASC have made situations worse (Raut et al., 2018). Further, food security programs are hampered due to food wastage in distribution (Timmer et al., 2014). Gustavsson et al. (2011) believed that one-third of food is lost in the journey of "Farm-to-Fork." Thus, there is a need to take suitable measures for building sustainable food security. To this effect, recent advancements 
in technologies have been a relief, and blockchain has emerged as a viable technology that could be utilized for improving sustainable food security system.

\subsection{Sustainable food security in India}

Food Security came into existence at the "World Food Conference in 1974" with an emphasis on supply. In the Indian context, both state and central governments jointly ensure that food security and benefits to the needy are provided through a "Public Distribution System" (PDS). Srivastav and Dubey (2004) studied the effectiveness of the food security system for India's north-eastern states. The authors found that PDS was not effective alone but needed poverty alleviation programs to ensure food security. Dame and Nüsser (2011) found similar results for the population living at high altitudes and claimed that PDS alone is not adequate, pushing the idea that policies need to be changed to ensure food security. However, Kattumuri (2011) further found that various other problems such as corruption and delays in PDS result in non-implementation of the fair system leading to food insecurity. Ramkrishna et al. (2012) emphasized the role of women and women development programs to ensure India's household food security. Furthermore, Ray et al. (2012) studied the growing population consumption patterns and suggested increasing the yield. Narayanan (2015) and Mogale et al. (2020) studied the PDS system and found that the focus of PDS is only on cereals and lacks the individual dietary requirements resulting in malnutrition.

Food security programs are badly affected due to manmade as well as natural calamities and result in loss of food production, access, and utility (Khandekar, 2013; Krejci \& Beamon, 2010). Under such circumstances, crop insurance is a viable solution. Raghuvanshi (2008) studied the government's role in designing crop policies in the Indian context. They attempted to show that a private insurance firm might be more beneficial for farmers due to market competition. Moreover, Lobell et al. (2008) emphasized upgrading crop types and plantation cycles to fight climatic change. Krejci and Beamon (2010) suggested using nontoxic and renewable inputs to develop environmentally sustainable ASC. The main focus of the proposed framework was to ensure food safety. More details on the impact on climate changes on global food security can be found in the work of Brahmanand et al. (2013) and Wheeler and Von Braun (2013). Irani and Sharif (2016) investigated the relationship between food security effectiveness programs and food wastage to ensure sustainable food security. Kaur (2021) advocated the use of Internet of Things (IoT) technologies to ensure sustainable food security. Due to increased awareness about food safety and security in the global market, the agro-organizations are forced to incorporate various technologies in their SC. Under such circumstances, a blockchain-enabled traceability and information system could play a pivotal role.

\subsection{Blockchain adoption in ASC}

Various researchers around the globe have studied the applications of blockchain with an agro-perspective. Zhao et al. (2019) reviewed the literature on blockchain-based applications in ASC. The authors found that the blockchain-based system in ASC is used for traceability, agri-food manufacturing, sustainable water management and information security. Yadav and Singh (2019a) also presented a literature review of blockchain-based research in agriculture. The author categorized blockchain-based research under four dimensions: traceability, architecture, information system, and other miscellaneous applications. The authors also believed that blockchain adoption is still a naïve stage. Tian (2016) presented the idea 
of using blockchain for food safety in conjunction with RFID. Similarly, Kshetri (2019) developed the potential of blockchain for enhancing food safety. Tian (2017) developed a traceability mechanism in ASC using blockchain and IoT. Iansiti and Lakhani (2017) studied the economics of blockchain adoption for traceability and found that blockchain is being used in several complex supply chains. Li and Wang (2018) also advocated the traceability of organic agriculture products using blockchain technology. George et al. (2019) discussed a blockchain-based system for reliable food traceability in an Indian restaurant. Behnke and Janssen (2020) discussed eighteen boundary conditions to incorporate blockchain-based food traceability. The boundary conditions were clustered into regulation, quality, business, and traceability. Salah et al. (2019) used the Ethereum platform to design blockchain-based traceability of soybean. Yadav and Singh (2019b) proposed a framework to address selected farmers' issues in the Indian context using blockchain-based mobile applications.

Kamilaris et al. (2019) studied blockchain trends in ASC and discussed some of the challenges for its adoption. These challenges include lack of government regulation, regularity uncertainty, lack of training and training platforms. Hughes et al. (2019) have also discussed various applications of blockchain along with their limitations. Kamble et al. (2020) discussed blockchain-enabled traceability and found that factors like traceability, provenance, suitability, and immutability were the most significant construct for blockchain implementation in ASC. Galvez et al. (2018) studied the problems encountered with traceability using the blockchain-based system. Leng et al. (2018) discussed the enhanced features for the security of blockchain through double chain architecture. Thakur et al. (2020) discussed various challenges for the implementation of blockchain-based mechanisms like a high initial investment, regularity uncertainty, and security related issues, etc. Other challenges for blockchain adoption in ASC include lack of skilled workforce, lack of government regulation, throughput and latency, storage capacity and scalability, privacy concerns and high cost, etc. (Zhao et al., 2019). The detailed applications of blockchain technology in ASC are developed in Table 1.

\subsection{Existing gaps and highlights in the research}

Indian ASC is very complex, unorganized, semi-integrated, and involves many intermediaries (Vishwadham \& Kameshwaran, 2013), which results in an inefficient agri-business environment. Moreover, food security programs are hampered due to losses in ASC through various activities like improper handling (Gardas et al., 2018), inadequate infrastructure (Kaur, 2021), and lack of proper marketing facilities (Raut et al., 2019) which make it difficult to ensure sustainable food security. The monitoring of PDS is not sufficient; further wastage, theft and corruption results in inefficient food distribution. Moreover, such situations give rise to other problems like corruption, malnutrition and increased poverty. Thus, to improve PDS, technology upgradation is necessary (Kaur, 2021). Blockchain is one such technology that can be integrated with PDS and other similar programs to ensure and monitor sustainable food security. However, blockchain adoption is still in the naïve stage (Ge et al., 2017; Zhao et al., 2019). In addition, no literature was found, which elaborates on the driving construct of blockchain for ensuring sustainable food security for the Indian context. Furthermore, modelling of these drivers for various decision making and strategy building is also missing in the literature. Thus, there is a need to identify and model the blockchain adoption drivers in the Indian ASC. Moreover, aligning strategy in conjunction with these drivers may enhance the adoption rate of blockchain, which will result in a win-win situation for all ASC stakeholders. To this effect, the factors are identified through a comprehensive literature search and with 
Table 1 The blockchain applications in ASC

\begin{tabular}{|c|c|c|c|c|c|}
\hline Sr. No & Author(s) & Year & Country & Approach & Area \\
\hline 1 & Tian & 2016 & China & Framework & $\begin{array}{l}\text { Traceability and food } \\
\text { safety }\end{array}$ \\
\hline 2 & Tian & 2017 & China & Implementation & $\begin{array}{l}\text { Traceability and food } \\
\text { safety }\end{array}$ \\
\hline 3 & $\begin{array}{l}\text { Iansiti \& } \\
\text { Lakhani }\end{array}$ & 2017 & - & Opinion & $\begin{array}{l}\text { Economics of } \\
\text { blockchain }\end{array}$ \\
\hline 4 & $\mathrm{Li}$ and Wang & 2018 & China & Opinion & $\begin{array}{l}\text { Traceability and food } \\
\text { safety }\end{array}$ \\
\hline 5 & Zheng et al & 2018 & - & Review & $\begin{array}{c}\text { Challenges and } \\
\text { opportunities }\end{array}$ \\
\hline 6 & Galvez et al & 2018 & - & $\begin{array}{l}\text { Review and case } \\
\text { study }\end{array}$ & $\begin{array}{l}\text { Challenges of } \\
\text { blockchain-enabled } \\
\text { traceability }\end{array}$ \\
\hline 7 & Leng et al & 2018 & China & Simulation & Blockchain architecture \\
\hline 8 & $\begin{array}{l}\text { Antonucci } \\
\text { et al }\end{array}$ & 2019 & - & Review & $\begin{array}{l}\text { Application in } \\
\text { agri-sector }\end{array}$ \\
\hline 9 & Cole et al & 2019 & - & Review & $\begin{array}{l}\text { Implications of } \\
\text { blockchain in } \\
\text { operations and supply } \\
\text { chain management } \\
\text { (OSCM) }\end{array}$ \\
\hline 10 & George et al & 2019 & India & $\begin{array}{l}\text { Field Survey and } \\
\text { implementation }\end{array}$ & Traceability \\
\hline 11 & $\begin{array}{l}\text { Hald and } \\
\text { Kinna }\end{array}$ & 2019 & - & Review & $\begin{array}{l}\text { Blockchain role in } \\
\text { enabling and } \\
\text { constraining SC } \\
\text { performance }\end{array}$ \\
\hline 12 & Kamble et al & 2020 & India & ISM-DEMATEL & $\begin{array}{l}\text { Blockchain-enabled } \\
\text { Traceability }\end{array}$ \\
\hline 13 & $\begin{array}{l}\text { Kamilaris } \\
\text { et al }\end{array}$ & 2019 & - & $\begin{array}{l}\text { Review and case } \\
\text { study }\end{array}$ & $\begin{array}{l}\text { Trends of blockchain } \\
\text { applications in ASC }\end{array}$ \\
\hline 14 & Kshetri & 2019 & - & Opinion & $\begin{array}{l}\text { Economics of } \\
\text { blockchain }\end{array}$ \\
\hline 15 & Kumar et al & 2020 & - & Sample use case & $\begin{array}{l}\text { Technical } \\
\text { implementation } \\
\text { challenges }\end{array}$ \\
\hline 16 & Lin et al & 2019 & & $\begin{array}{l}\text { Software } \\
\text { Implementation }\end{array}$ & $\begin{array}{l}\text { Traceability, food } \\
\text { safety, and smart } \\
\text { contract }\end{array}$ \\
\hline 17 & Pearson et al & 2019 & - & $\begin{array}{l}\text { Conceptual } \\
\text { Proposal }\end{array}$ & Traceability \\
\hline 18 & $\begin{array}{l}\text { Queiroz and } \\
\text { Wamba }\end{array}$ & 2019 & $\begin{array}{l}\text { USA and } \\
\text { India }\end{array}$ & PLS-SEM & Adoption behavior \\
\hline
\end{tabular}


Table 1 (continued)

\begin{tabular}{|c|c|c|c|c|c|}
\hline Sr. No & Author(s) & Year & Country & Approach & Area \\
\hline 19 & Salah et al & 2019 & - & Implementation & Traceability \\
\hline 20 & Wang et al & 2019 & - & $\begin{array}{l}\text { Review and use } \\
\text { cases }\end{array}$ & $\begin{array}{l}\text { Diffusion of blockchain } \\
\text { in supply chain }\end{array}$ \\
\hline 21 & $\begin{array}{l}\text { Yadav and } \\
\text { Singh }\end{array}$ & $2019 a$ & - & Review & $\begin{array}{l}\text { Traceability, } \\
\text { information system, } \\
\text { security, and } \\
\text { architecture }\end{array}$ \\
\hline 22 & $\begin{array}{l}\text { Yadav and } \\
\text { Singh }\end{array}$ & $2019 b$ & India & $\begin{array}{l}\text { Delphi and } \\
\text { framework }\end{array}$ & $\begin{array}{l}\text { Selected issues of } \\
\text { Indian Farmers }\end{array}$ \\
\hline 23 & Zhao et al & 2019 & - & Review & $\begin{array}{l}\text { Applications of } \\
\text { blockchain in ASC }\end{array}$ \\
\hline 24 & $\begin{array}{l}\text { Behnke and } \\
\text { Janssen }\end{array}$ & 2020 & Netherland & $\begin{array}{l}\text { Structured } \\
\text { Interview }\end{array}$ & Traceability \\
\hline 25 & Hang et al & 2020 & - & Simulation & $\begin{array}{l}\text { Data integrity for fish } \\
\text { farm platform }\end{array}$ \\
\hline 26 & Thakur et al & 2020 & India & Framework & Land registration \\
\hline 27 & $\begin{array}{l}\text { Wamba and } \\
\text { Queiroz }\end{array}$ & 2020 & - & $\begin{array}{l}\text { Editorial-Special } \\
\text { Issue }\end{array}$ & $\begin{array}{l}\text { Blockchain } \\
\text { applications in } \\
\text { OSCM }\end{array}$ \\
\hline
\end{tabular}

the help of a team of concerned domain experts. Further, we intended to develop a structural model that would not only build a hierarchy to investigate the interrelation amongst adoption drivers of blockchain in ASC but also evaluate the intensity of the relationship between them. The model further categorizes the identified construct into suitable clusters to take adequate measures at a broader scale to reap blockchain adoption benefits.

\section{Research methodology}

In literature, critical constructs are modeled using various Multi-Criteria Decision Making (MCDM) tools, out of which; Interpretive Structural Modelling (ISM) is very popular; Unlike other MCDM techniques such as ANP, AHP and TOPSIS, ISM does not require the intensity of the relationship amongst constructs (Gardas et al., 2019a). This results in improved accuracy in the model through reduced biasness of experts. Although, a few authors criticize ISM applications as they fail to interpret some essential transitive links (Lamba \& Singh, 2018; Sushil, 2012). The other concern is that ISM only focuses on nodes and has an inferior interpretation of links (Gardas et al., 2019a; Sushil, 2018). To overcome such problems, Total Interpretive Structural Modelling (TISM) is an ideal solution, which eliminates the shortcomings of ISM. TISM helps to transform a weakly articulated rational model into a well-defined and straightforward model (Pathak et al., 2019; Sushil, 2017). Hence, this research makes use of TISM to interrogate blockchain adoption drivers to achieve sustainable food security. However, the contextual relation in TISM is shown through the binary number ( 1 means that a relationship exits and 0 means that there is no relationship). So, wherever 
there exist any contextual relationship between two constructs, equal weight is assigned in the TISM model, which may not represent the real picture of the actual scenario and may result in the poor interpretation of the model. For such instance, to get better structuring of the model, the intensity of the relationship may be incorporated. The relationships may range from very low to very strong (Bhosale \& Kant, 2016). DEMATEL is one such technique that can model the intensity of the relationship between the concerned construct. However, traditional DEMATEL cannot incorporate any vagueness or uncertainty in the response, which results in an inferior quality of solutions. Thus to overcome such instances, the use of fuzzy DEMATEL is suggested (Keskin, 2015). Thus, in this work, an integrated approach of TISM Fuzzy-DEMATEL is used. Furthermore, Fuzzy MICMAC is also used to cluster the identified drivers in suitable categories in order to understand the importance of each driver. These methodologies are elaborated in subsequent sub-sections. The blockchain adoption drivers are identified through an exhaustive literature search and the opinions of domain experts from industry and academia, as well as agro-stakeholders. The roadmap of the study is given in Fig. 1.

\subsection{TISM}

Sushil (2012) proposed the Total Interpretive Structural Modelling (TISM), which makes use of an interpretive matrix to interpret directed or undirected links or binary relationships (Mangla et al., 2014), allowing for better elaboration of structures/models. The steps of TISM, as illustrated by Gardas et al. (2019a), are as follows:

Step 1: Identification of the construct amongst which interrelationships are to be studied.

Step 2: Determination of contextual/mutual relationships between identified constructs. E.g., the contextual relationship between two constructs may be assigned in terms of "P help to achieve R."

Step 3: The relationships obtained in step two are interpreted.

Step 4: Development of "interpretative logic for pairwise comparison." As traditional ISM only interprets one direction of the relationships, TISM employs the "interactive matrix concept" to get more in-depth information. Under such an approach, the pairwise comparison is made between the $i$ th element and all other elements. The relationship may be either $\mathrm{Y}$ (Yes) or $\mathrm{N}$ (No). If an answer is $\mathrm{Y}$, the corresponding interpretations are evaluated.

Step 5: Construction of a reachability matrix followed by a transitive check. The "Y" and "N" entries are converted to binary ("Y $=1$ and $\mathrm{N}=0$ "), and transitivity links are added if they are present and significant. The corresponding transitive links are updated and their interpretation is added following the "interpretative knowledge rule base," as mentioned in Step 4.

Step 6: Level partitioning based on the reachability matrix (explained in the next section).

Step 7: Development of a Diagraph. The diagraph is plotted by organizing the elements at their respective levels and direct links are connected as per the relationship obtained from the reachability matrix. It is worth noting that some significant transitive links may be retained.

Step 8: Determination of the interpretive matrix. The interpretive matrix is obtained by transforming diagraph into a binary matrix, which indicates a significant relationship. " 1 " in the binary matrix indicates the existence of a relationship, and corresponding interpretation statement is written in the "interpretive matrix." 


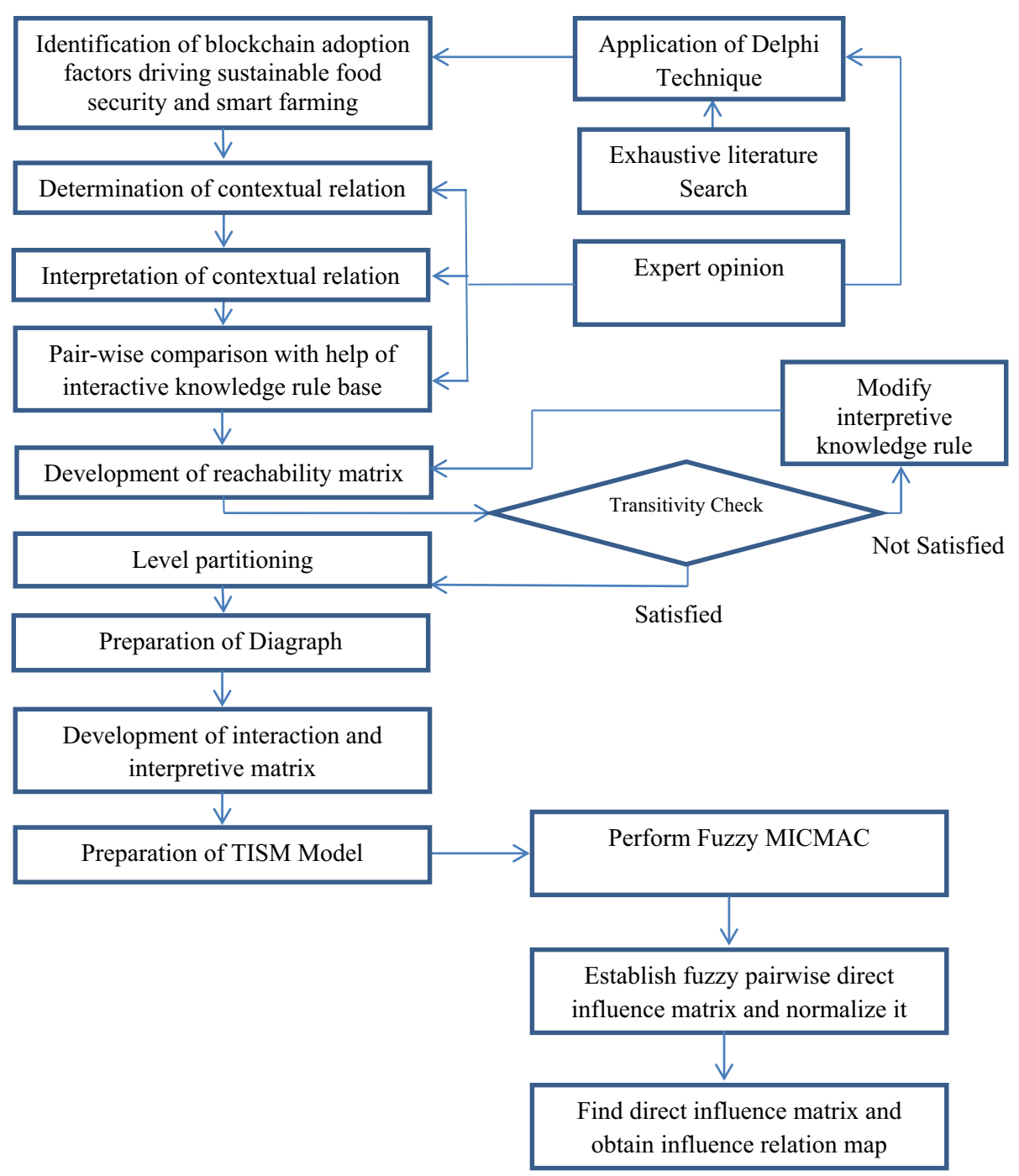

Fig. 1 Research Methodology

Step 9: Develop the TISM model. It is obtained with the help of the interpretive matrix and diagraph. The nodes in a digraph are replaced by actual construct name, and interpretive matrix information is also highlighted on the links of the TISM model.

\subsection{Fuzzy MICMAC}

TISM is followed by carrying out a MICMAC analysis, which is a suitable methodology for clustering of the construct. MICMAC analysis also gives the dependence and driving power of each construct. However, traditional MICMAC is often subjected to criticism as it considers equal relations between constructs even when there are relationships which are not valid in 
actual practice in the case when each construct have a different level of association with one another (Bhosale \& Kant, 2016; Khurana et al., 2010; Raval et al., 2018). To overcome such limitations, we employ Fuzzy MICMAC in this work. The steps used in "Fuzzy MICMAC analysis" are taken from Bhosale and Kant (2016).

Step 1: "Binary direct relationship matrix (BDRM)" is acquired by considering all diagonal elements as zero, and rest are unchanged in the IRM matrix.

Step 2: Develop a "linguistic assessment direct reachability matrix (LADRM)."

Step 3: Develop a "Fuzzy MICMAC-stabilized matrix."

Step 4: Obtain the driving and dependence powers of each construct and draw the MICMAC plot to obtain various clusters.

\subsection{Fuzzy DEMATEL}

DEMATEL is developed by the "Geneva Research Centre of the Battelle Memorial Institute" for visualizing the complicated causal relationship structure through matrixes and diagraphs (Gabus and Fantela, 1972). DEMATEL uses an impact relation diagram to evaluate the most critical factors and transform interdependency relationships into cause and effects groups through diagraph and matrices (Kaur et al., 2018; Si et al., 2018). Fuzzy DEMATEL can incorporate any vagueness or uncertainty in response, which results in more accurate findings. Moreover, we have considered "Triangular Fuzzy Numbers (TFN)" in this work due to simplicity and common usage in many publications globally (Yeh \& Deng, 2004). TFN is denoted as $\tilde{A}_{1}=(l, m, u)$ where " $l, m, u$ is the lower, middle and upper value" respectively (Fig. 2). They $l, m$ and $u$ are $x$-coordinates vertices of membership function, $\left(\mu_{\bar{A}}(x)\right)$ which maps fuzzy set $A$ input into real number interval [0,1]. The membership function $\left(\mu_{\bar{A}}(x)\right)$ is given by the following Eq. 1 .

$$
\mu_{\bar{A}}(x)=\left[\begin{array}{cc}
0 & x<l \\
\frac{x-l}{m-l} & l \leq x \leq m \\
\frac{u-x}{u-m} & m \leq x \leq u \\
0 & x>u
\end{array}\right]
$$

The Fuzzy DEMATEL steps used for calculations are as follows:

Step1: Compute the group "fuzzy average direct influence relationship matrix": The identified constructs are evaluated by experts for pairwise comparison. For comparison,

Fig. 2 Triangular Fuzzy Number (TFN)

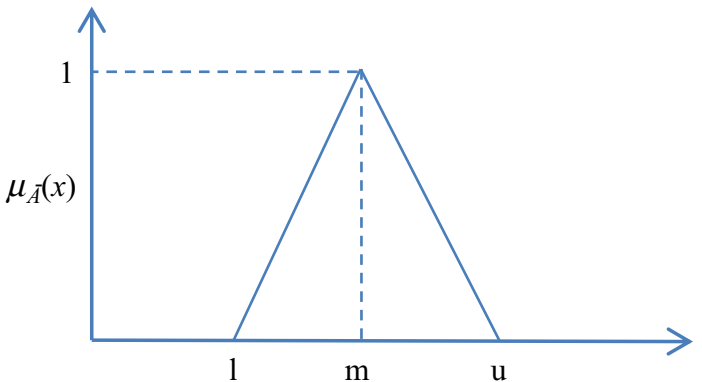


a fuzzy linguistic scale is considered (i.e. "No influence- $(0,0.1,0.3)$; Very low influence- $(0.1,0.3,0.5)$; Low influence- $(0.3,0.5,0.7)$; High influence $(0.5,0.7,0.9)$; Very high influence- $(0.7,0.9,1)$ "). Each expert gives his /her opinions. Suppose $\tilde{A}_{i j}^{p}=\left(\tilde{l}_{i j}^{p}, \tilde{m}_{i j}^{p}, \tilde{u}_{i j}^{p}\right)$, where $p=1,2,3, \ldots, m$ denotes the influence of $i$ th construct on $j$ th construct and is represented as

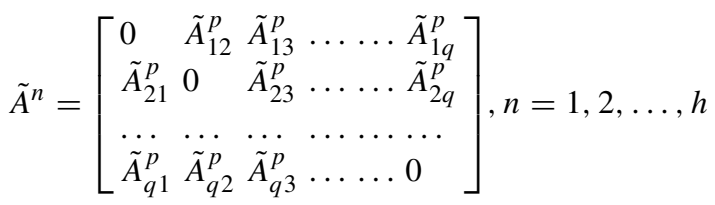

Where $q=$ number of construct and $m=$ number of experts

Here the inputs are fuzzy numbers, which lead to complexity in the mathematical computation process. For this, defuzzification is carried out to get crisp values. We have used the method of best non-fuzzy performance (BNP) as illustrated in Bhosale and Kant (2016) for defuzzification. The formula to obtain BNP is given in Eq. 3 .

$$
B N P_{i j}=\frac{(u-1)+(m-1)}{3}+l
$$

Moreover, the "average direct influence matrix" $Z=\left[z_{i j}\right]$ is computed as an averaging each expert direct influence matrix.

Step 2: Normalize the "direct influence matrix": The normalized average "direct influence matrix" $\left(D=\left[d_{i j}\right]_{q * q}\right)$ is given by Eq. 4 :

$$
D=\frac{z}{s}
$$

Where

$$
s=\max \left(\max _{1 \leq i \leq q} \sum_{j=1}^{q} x_{i j}, \max _{1 \leq i \leq q} \sum_{i=1}^{q} x_{i j}\right)
$$

Every element in matrix $D$ obeys the rule $0 \leq d_{i j} \leq 1,0 \leq \sum_{j=1}^{q} d_{i j} \leq 1$ and we have at least one $i$ such that $\sum_{j=1}^{q} z_{i j} \leq s$.

Step 3: Find the "total influence matrix": The "total influence matrix" $T=\left[t_{i j}\right]_{q * q}$ is calculated by Eq. 6 :

$$
T=D+D^{2}+D^{3}+\cdots+D^{c}=D(1-D)^{-1}
$$

Where $C \rightarrow \infty$ and $I$ is denoted as an identity matrix.

Step 4: Formulate the "influence relationship map": To draw the "influence relationship map" two vectors, namely $R$ and $C$ are computed, which are nothing but the sum of rows and columns respectively in the "total influence matrix $(T) . "$

$$
\begin{aligned}
& R=\left[r_{i}\right]_{q * 1}=\left[\sum_{j=1}^{n} t_{i j}\right]_{q * 1} \\
& C=\left[c_{i}\right]_{1 * q}=\left[\sum_{i=1}^{n} t_{i j}\right]_{1 * q}
\end{aligned}
$$

Where $r_{i}$ denotes the "sum of direct and indirect influence" of construct $q_{i}$ on other constructs while $c_{j}$ denotes the "sum of direct and indirect influence" that construct $q_{i}$ is getting from other constructs. These two vectors are utilized to get the "influence relationship map" where $(R+C)$ is considered as the $x$ axis and $(R-C)$ as the $y$ axis for each construct. On horizontal axis, the $(R+C)$ value, also called the "Prominence" of a construct, denotes its strength and 
is also a central part of the system. Whereas on the vertical axis $(R-C)$ also known as the "Relation" is the net effect of the construct, which it puts on the system. If $\left(r_{i}-c_{j}\right)$ value of a construct is positive, it shows that this construct has a net influence on other constructs and can be clustered into the cause group. Conversely, if $\left(r_{i}-c_{j}\right)$ is negative, the particular construct is influenced by another construct in the system and can be clustered into the effect group.

\section{Application of proposed methodology}

The blockchain drivers for sustainable food security are obtained through an exhaustive literature search and from the opinions of domain experts. For the literature search, the online digital databases of Scopus, Sciencedirect, Emeraldinsight, IEEE Explorer, Google Scholar and Web of Science are used. Furthermore, domain experts from academia and industry are also consulted on the concerned topic and two rounds of Delphi procedure are developed to reach a consensus. More emphasis is given to select experts from industry. At the end, the expert panel includes a significant number of academician and ASC stakeholders.

The criteria considered in the selection of experts are the past experience, the position held, and the expertise in the primary knowledge domain. For this, fifty-two experts were contacted, including twenty-nine people from industry, eleven academicians, and twelve ASC stakeholders. Amongst them, twenty one persons agreed to participate in the study. The study's nature is responsible for low sample as the blockchain is a new technology. Additionally, since the study considers a big number of variables, the time expected to spend on the Delphi procedure was considered as long, resulting in a lower response rate.

At the end, the participating experts included three backend blockchain developers, five senior-level managers from agro-industries, three professors from engineering institutions, two professors from management institutions, and one chief executive officer (CEO) from an agro-industrial company, and seven other ASC stakeholders. Each blockchain developer had a minimum experience of six years in executing blockchain-related projects for various industrial projects. Each senior-level manager had experience in concerned industries for more than fifteen years. The professors had experience of twenty years while the CEO had experience running the organization from last twenty-three years. The agro-stakeholder constituted of two farmers, three people from agro-marketing and two consumers. The farmers had little knowledge of the concerned subject but were quite aware of the concept. The agromarketing people were using the blockchain-based system for some of their operations, while consumers were the beneficiaries of some of these activities.

According to Cole et al. (2019), the characteristics of blockchain include smart contract, immutable databases, distributed and synchronized across networks and peer-to-peer (P2P) network. These characteristics are also used as drivers in the literature by many researchers as addressed and discussed in Table 2, in which 14 drivers are identified and reported as the main blockchain adoption drivers. Furthermore, the experts taking part to this study objectively assess these characteristics as being the driving forces for adoption of blockchain and hence, they can be considered as blockchain drivers.

It is important to understand the specific characteristics of blockchain that help to achieve the identified drivers; Smart contracts are self-executing and digitally verified computer protocol, which are full-proof through cryptography. Furthermore, smart contract can verify and match the pre-specified agreement between supplier and buyer and trigger payments. In addition, whenever the key milestones in pre-specified agreement are met, it autonomously 


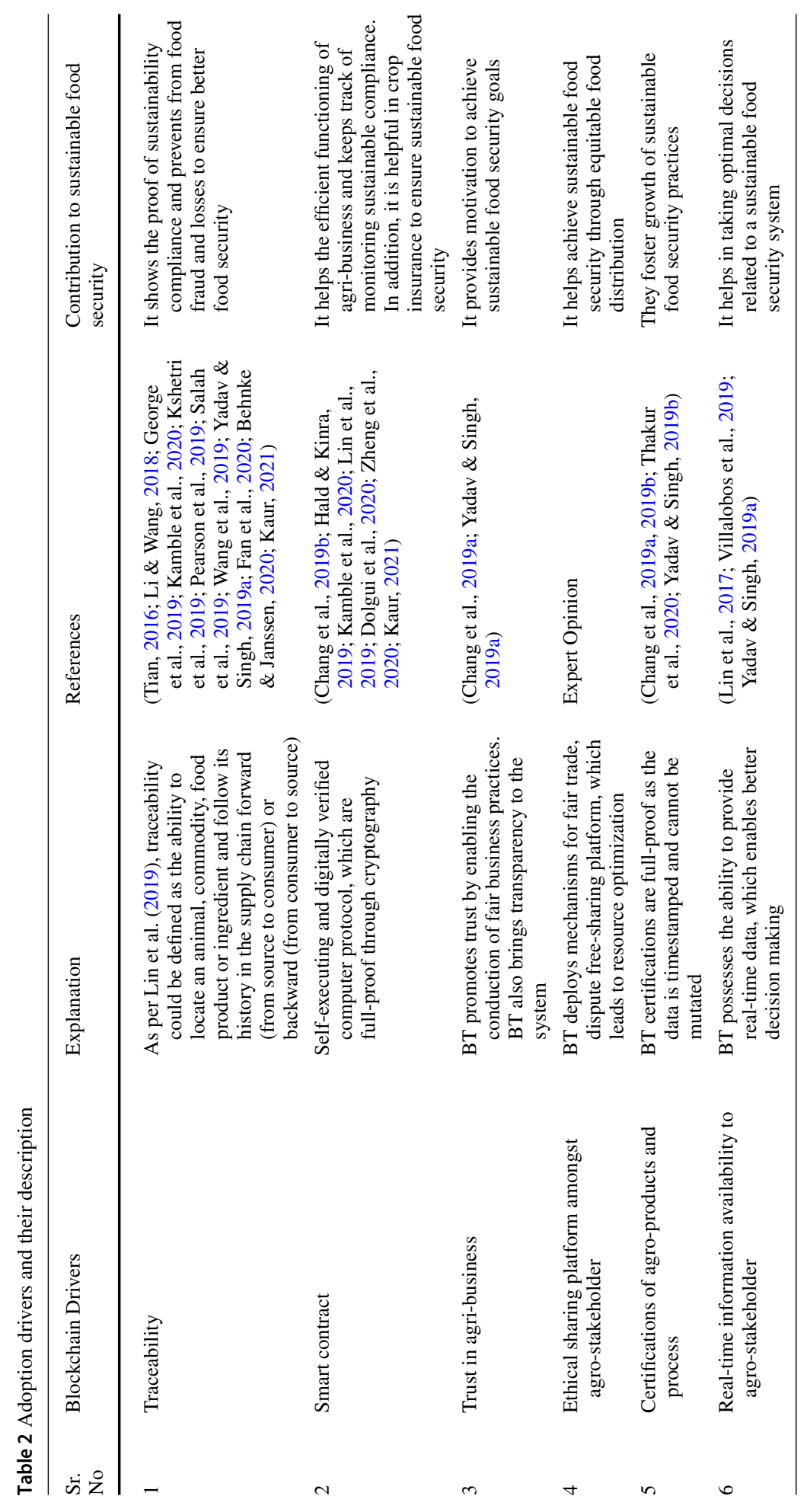




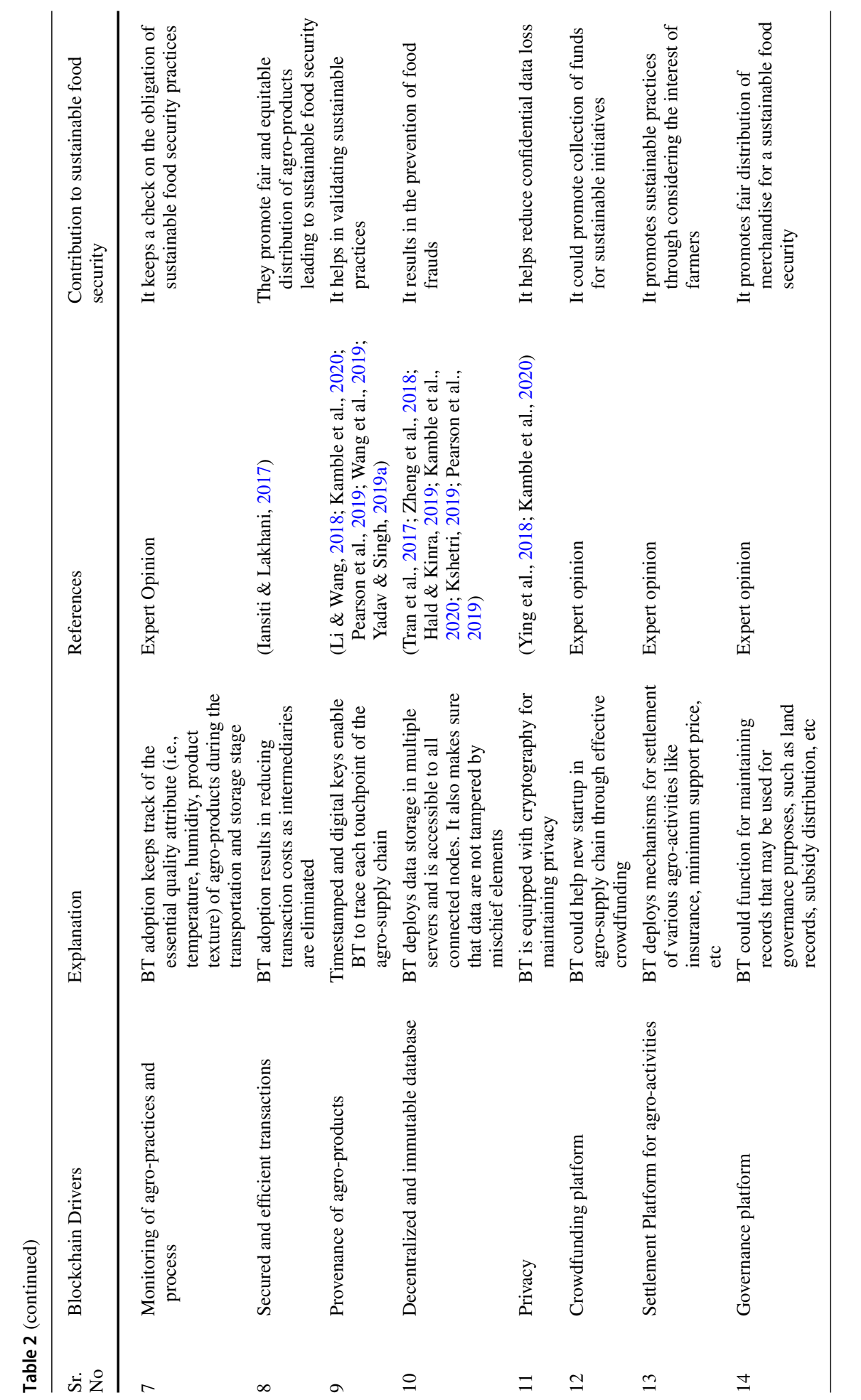


triggers the specified payment. In this way, smart contracts facilitate the secured and efficient transactions (BD8) and create foundation of trust in agri-business (BD3). Moreover, the ability to perform pre-specified agreement is helpful in peaceful settlement (BD13), ethical sharing (BD4) and governance (BD14) of various agro-activities. The characteristics of blockchain to maintain immutability of data prevents forgery in paperwork and enhances auditability. Thus, it facilitates the traceability (BD1), certification (BD5) and provenance of agro-products (BD9). The other characteristics of blockchain i.e. distributed and synchronized platform across networks provide real-time data access to each partner. Thus, it acts as information system (BD6) and ensures traceability (BD1), certification (BD5) and provenance of agroproducts (BD9). As the blockchain based system is P2P based, it ensures privacy (BD11) for each partner of the blockchain network and can be subsequently used as a crowdfunding platform (BD12).

\subsection{Application of TISM methodology}

The methodology explained in the third section of the paper is used to model the blockchain drivers for sustainable food security. In the subsequent section, the contextual relation, reachability matrix, and level partitioning are presented, while the interaction and interpretative matrix are presented in Appendix A.

\subsubsection{Contextual relation and aggregation in the form of SSIM}

The contextual relationship is obtained using four symbols (i.e., V, A, X, O) in the form of a "self-structural interaction matrix (SSIM)." Each of these symbols has a different meaning, which is explained as follows:

"V: Means construct $i$ influences construct $j$.

A: Means construct $i$ is influenced by construct $j$.

$\mathrm{X}$ : Means construct $i$ and construct $j$ influence each other.

$\mathrm{O}$ : Means there is no influence between constructing $i$ with construct $j$ and vice-versa".

\subsection{2 "Development of "initial and final reachability matrix"}

SSIM matrix is changed to binary $(1,0)$ numbers to get an "initial reachability matrix (IRM)" through the following rules:

- "If $(i, j)$ entry in SSIM is V, then it is replaced by 1 , and corresponding $(j, i)$ entry becomes 0 in IRM."

- "If $(i, j)$ entry in SSIM is A, then it is replaced by 0 , and corresponding $(j, i)$ entry becomes 1 in IRM."

- "If $(i, j)$ entry in SSIM is X, then it is replaced by 1 , and corresponding $(j, i)$ entry also becomes 1 in IRM."

- "If $(i, j)$ entry in SSIM is O, then it is replaced by 0 , and corresponding $(j, i)$ entry also becomes 0 in IRM."

Subsequently, the transitivity rule is applied to get the "final reachability matrix (FRM) from an initial reachability matrix." The transitivity rule says if construct $i$ affects construct $j$ and construct $j$ affects construct $k$, then construct $i$ automatically affects construct $k$. The FRM is shown in Table 3. The transitive links are shown using an asterisk (*). 


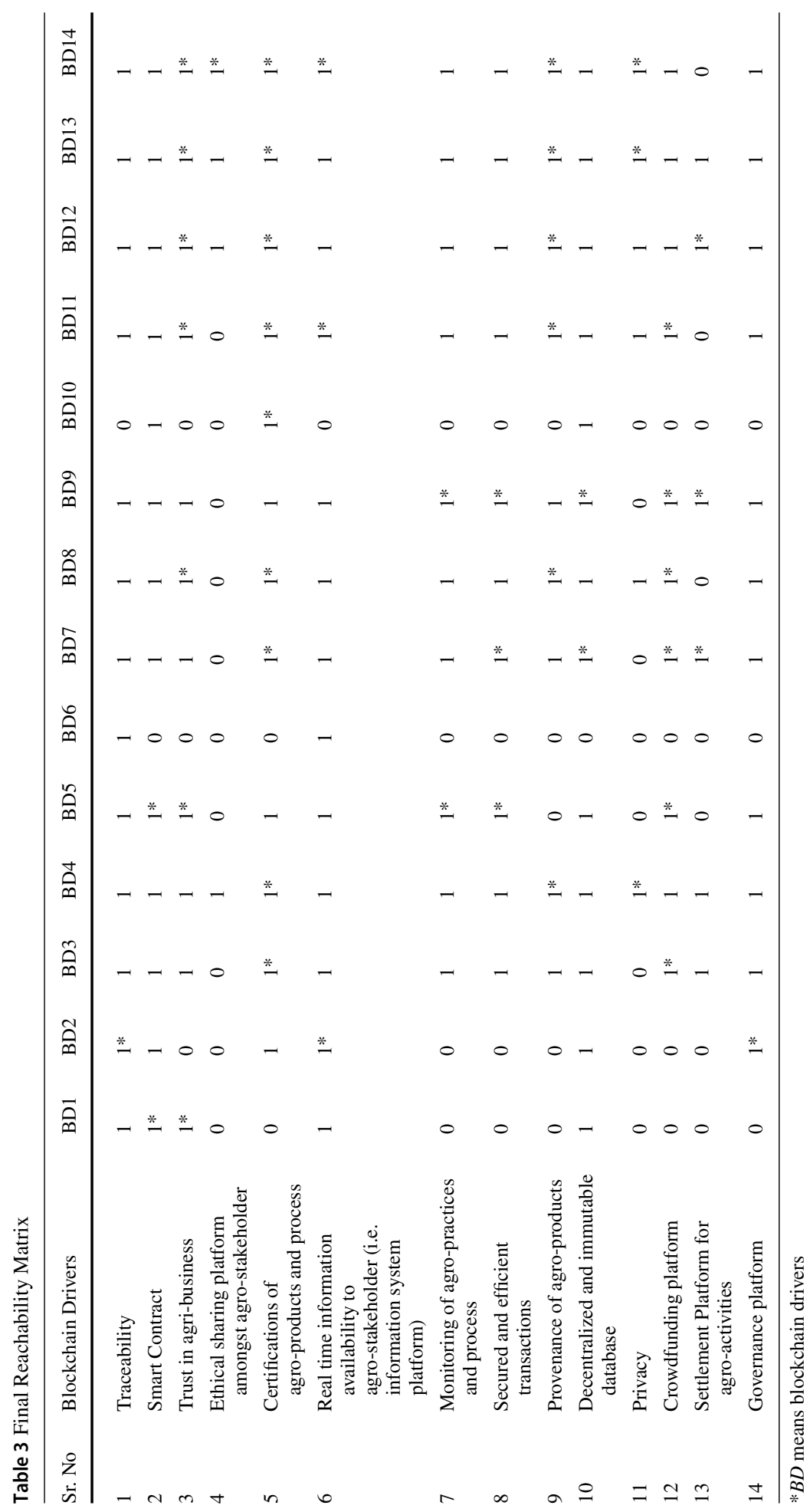




\subsubsection{Level partitioning}

The "Final reachability matrix" is utilized for level partitioning. For this, three sets for each construct are developed, namely "reachability set, antecedently set an intersection set." Reachability set of a construct consists of all those elements on which it influences, while an antecedent set of construct consist is all those elements that influence this particular construct. Furthermore, the intersection set is a common element from the other two sets, i.e., "reachability and antecedent." Also, for the construct whose reachability set an intersection set are the same, they are considered the top level of ISM hierarchy (Sage, 1977). All other constructs at a lower level than this will help achieve these constructs. Once these constructs are identified, they are removed from for the next iteration where a similar process is repeated until all constructs are assigned to an appropriate level. The level partitioning is shown in Table 4. This information is used to make a diagraph where the significant transitive element may be retained. Further, this digraph is transformed into a TISM model where the actual construct name replaces a node in a digraph. Here, we have not drawn a diagraph due to the space limitations of the paper. The TISM model is directly shown in Fig. 3, whereas the description of the model is addressed and discussed in the result and discussion section.

Table 4 Level partitioning

\begin{tabular}{lllll}
\hline $\begin{array}{l}\text { BD } \\
\text { No }\end{array}$ & Reachability Set & Antecedent Set & Interaction Set & Level \\
\hline 1 & $1,2,3,4,5,6,7,8,9,11,12,13,14$ & $1,3,6$ & & \\
2 & $2,3,4,5,7,8,9,10,11,12,13,14$ & $1,2,5,6,10,14$ & $1,3,6$ & V \\
3 & $1,3,4,5,7,8,9,11,12,13,14$ & $1,2,3,5,6,7,8,9,10,12,13,14$ & $2,5,10,14$ & IV \\
4 & $4,12,13,14$ & $1,2,3,4,5,6,7,8,9,10,11,12,13,14$ & $4,12,13,14$ & II \\
5 & $2,3,4,5,7,8,9,10,11,12,13,14$ & $1,2,3,5,6,7,8,10,12,14$ & $2,3,5,7,8,10,12,14$ & IV \\
6 & $1,2,3,4,5,6,7,8,9,11,12,13,14$ & 1,6 & $1,2,3,6,7,8,9,13,14$ & V \\
7 & $3,4,5,7,8,9,11,12,13,14$ & $1,2,3,5,6,7,8,9,10,12,13,14$ & $3,5,7,8,9,12,13,14$ & III \\
8 & $3,4,5,7,8,9,11,12,13,14$ & $1,2,3,5,6,7,8,9,10,11,12,14$ & $3,5,7,8,9,11,12,14$ & II \\
9 & $3,4,7,8,9,11,12,13,14$ & $1,2,3,5,6,7,8,9,10,12,13,14$ & $3,7,8,9,12,13,14$ & III \\
10 & $1,2,3,4,5,7,8,9,10,11,12,13,14$ & 2,10 & 2,10 & V \\
11 & $4,8,11,12,13,14$ & $1,2,3,5,6,7,8,9,10,11,12,14$ & $8,11,12,13,14$ & II \\
12 & $3,4,5,7,8,9,11,12,13,14$ & $1,2,3,4,5,6,7,8,9,10,11,12,13,14$ & $3,4,5,7,8,9,11,12,13,14$ & I \\
13 & $3,4,7,9,12,13$ & $1,2,3,4,5,6,7,8,9,10,11,12,13,14$ & $3,4,7,9,12,13$ & I \\
14 & $2,3,4,5,7,8,9,11,12,13,14$ & $1,2,3,4,5,6,7,8,9,10,11,12,14$ & $2,3,4,5,7,8,9,11,12,14$ & II \\
\hline
\end{tabular}




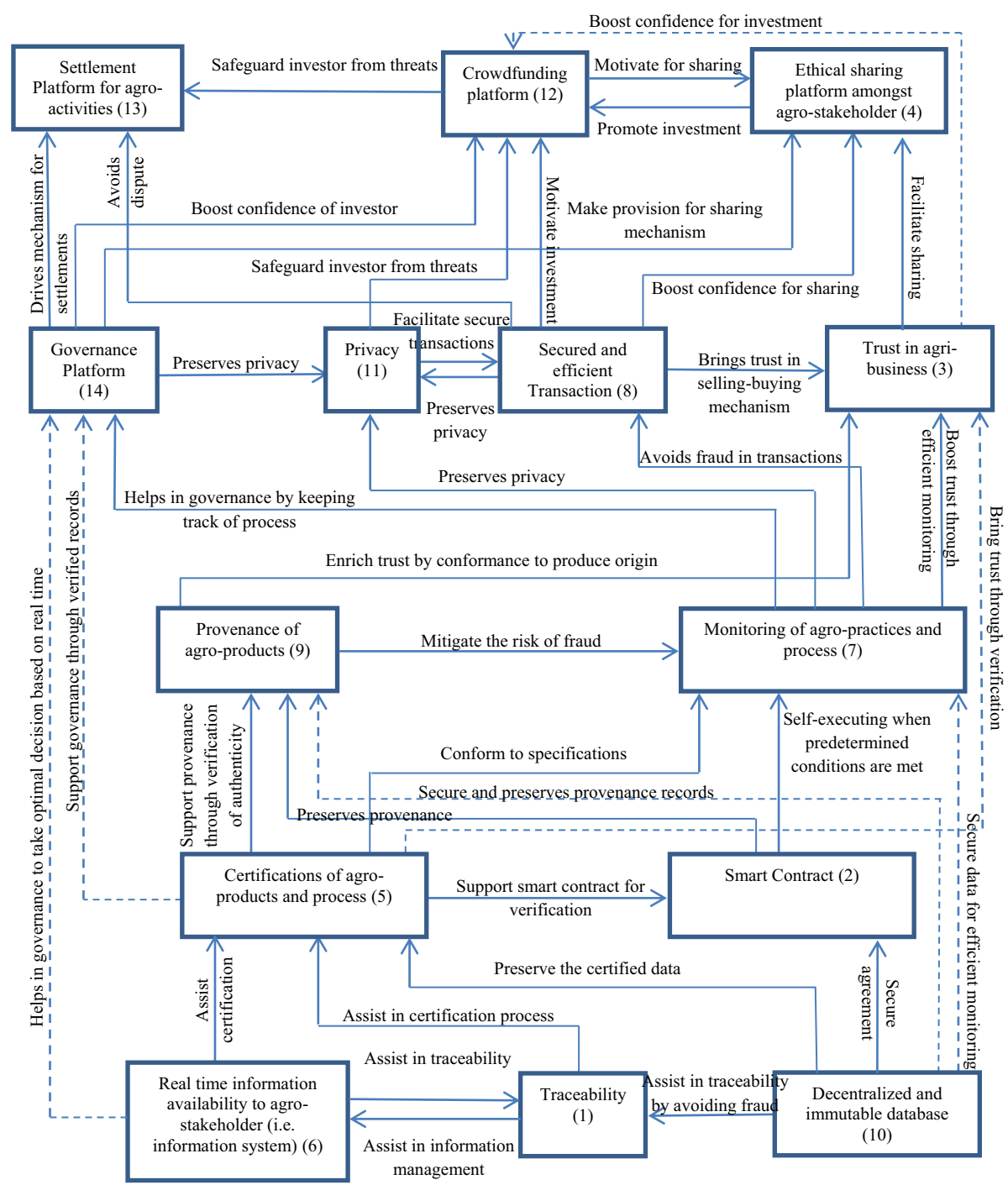

Fig. 3 TISM Model

\subsection{Fuzzy MICMAC}

\subsection{1 "Development of "Binary direct relationship matrix (BDRM)" and "linguistic assessment direct reachability matrix (LADRM)"}

BDRM is obtained by making all diagonal elements as zero in IRM matrix. As, the traditional MICMAC consider the binary number, which is not a true representation of the actual scenario (Bhosale \& Kant, 2016; Khurana et al., 2010). Hence it could be further improved by using Fuzzy Set Theory for better decision making and clustering of the identified construct. For this, we have considered the same fuzzy approach, as explained in Sect. 3.4 of this paper. The 
linguistic fuzzy scale used is as follows: "No influence (No)- $(0,0,0)$; Very low influence (VL)— $(0,0.1,0.3)$; Low influence $(\mathrm{L})-(0.1,0.3,0.5)$; Medium influence $(\mathrm{M})-(0.3,0.5$, $0.7)$; High influence $(\mathrm{H})-(0.5,0.7,0.9)$; Very high influence $(\mathrm{VH})-(0.7,0.9,1)$; Complete influence $(\mathrm{C})-(1,1,1)$." To rate the relationship between the considered construct, the responses of the same experts who participated in an earlier phase of studies were considered. These responses were superimposed on BDRM to get LADRM as shown in Appendix B of this paper. Since the calculation of fuzzy numbers is cumbersome, they are further defuzzified using Eq. 3 (i.e. "best non-fuzzy performance)." The defuzzified direct matrix (DDM) is shown in Appendix C.

\subsubsection{Development of "Fuzzy MICMAC-stabilized matrix" and plotting Fuzzy MICMAC diagram}

The defuzzified direct matrix and BDRM matrix is subjected to matrix multiplication, which is continued unless the dependence and driving power are stabilized. This is done by the rule of Fuzzy matrix multiplication (FMM) as illustrated by Kandasamy et al. (2007). FMM obeys the rule of Boolean matrix multiplication. The multiplication of two fuzzy matrices is also a fuzzy matrix that follows the condition:

$$
C=A, B=\max k\left[\left(\min \left(a_{i k}, b_{k j}\right)\right)\right] \quad \text { where } A=\left[a_{i k}\right] \text { and } B=\left[B_{k j}\right]
$$

The stabilized matrix is illustrated in Appendix D of this paper. The summation of the element in a particular row gives the driving power of that construct while the sum of the columns give the dependence power of that construct. Both of them are shown in Appendix D. This information is used to plot the Fuzzy MICMAC diagram, as shown in Fig. 4.

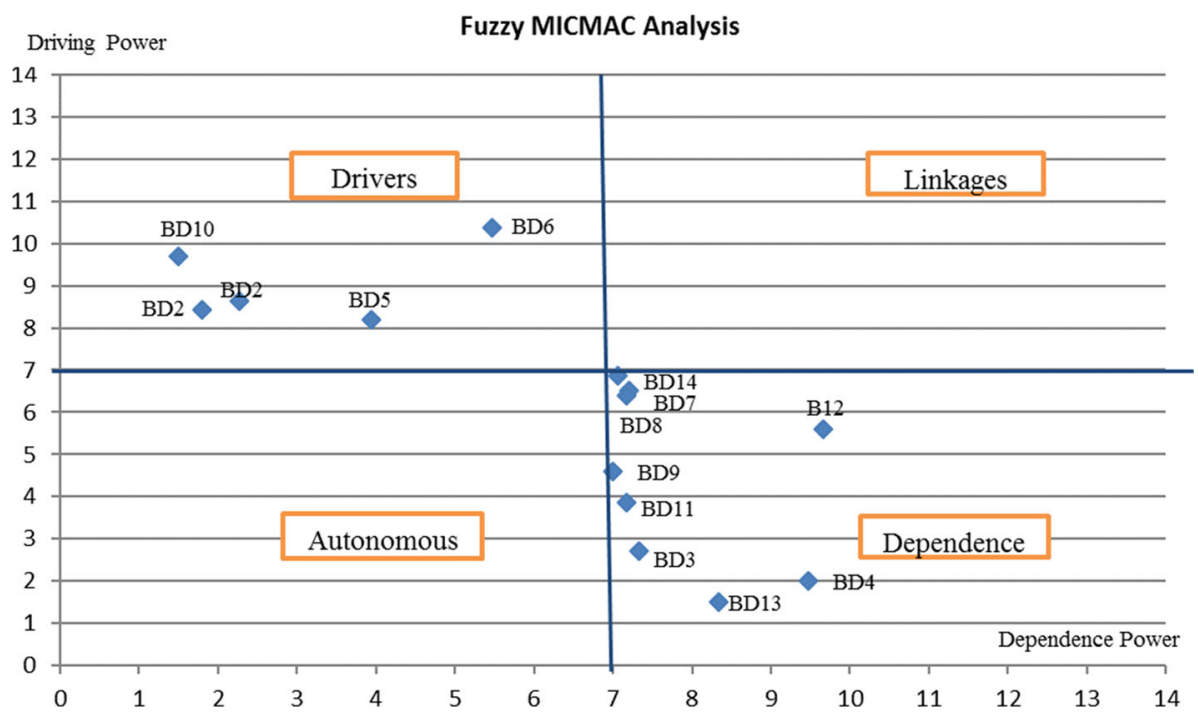

Fig. 4 Fuzzy MICMAC Analysis 


\subsection{Fuzzy DEMATEL}

The output of the TISM model is used as the input for Fuzzy DEMATEL. The intensity of the relationship between the construct where interrelationship exists was asked from the same expert as in earlier phases of the study. Further, as discussed in Sect. 3.3, fuzzy computation is cumbersome: thus the responses of each expert are defuzzified and are averaged to get "defuzzified direct relationship matrix (DDRM)" as shown in Table 5. DDRM is normalized, and the "normalized direct relationship matrix (NDRM)" is presented in Table 6. Further,

Table 5 Average direct matrix

\begin{tabular}{|c|c|c|c|c|c|c|c|c|}
\hline & BD1 & BD2 & BD3 & BD4 & BD5 & BD6 & BD7 & BD8 \\
\hline BD1 & 0.0000 & 0.7889 & 0.7000 & 0.5667 & 0.7444 & 0.7889 & 0.6778 & 0.5000 \\
\hline BD2 & 0.7000 & 0.0000 & 0.7000 & 0.5667 & 0.5000 & 0.0000 & 0.6778 & 0.8333 \\
\hline BD3 & 0.3000 & 0.0000 & 0.0000 & 0.6333 & 0.3667 & 0.0000 & 0.4333 & 0.4333 \\
\hline BD4 & 0.0000 & 0.0000 & 0.0000 & 0.0000 & 0.0000 & 0.0000 & 0.0000 & 0.0000 \\
\hline BD5 & 0.0000 & 0.6333 & 0.5000 & 0.5667 & 0.0000 & 0.0000 & 0.5667 & 0.5667 \\
\hline BD6 & 0.8333 & 0.7222 & 0.5667 & 0.5000 & 0.7889 & 0.0000 & 0.7222 & 0.4333 \\
\hline BD7 & 0.0000 & 0.0000 & 0.5000 & 0.5667 & 0.3000 & 0.0000 & 0.0000 & 0.6667 \\
\hline BD8 & 0.0000 & 0.0000 & 0.5444 & 0.5667 & 0.3667 & 0.0000 & 0.4333 & 0.0000 \\
\hline BD9 & 0.0000 & 0.0000 & 0.5000 & 0.5000 & 0.0000 & 0.0000 & 0.5000 & 0.5000 \\
\hline BD10 & 0.7444 & 0.8333 & 0.6333 & 0.7222 & 0.8333 & 0.0000 & 0.7889 & 0.8333 \\
\hline BD11 & 0.0000 & 0.0000 & 0.0000 & 0.7000 & 0.0000 & 0.0000 & 0.0000 & 0.4333 \\
\hline BD12 & 0.0000 & 0.0000 & 0.3000 & 0.3000 & 0.3000 & 0.0000 & 0.3000 & 0.3000 \\
\hline BD13 & 0.0000 & 0.0000 & 0.3667 & 0.7000 & 0.0000 & 0.0000 & 0.3667 & 0.0000 \\
\hline \multirow[t]{2}{*}{ BD14 } & 0.0000 & 0.3667 & 0.3667 & 0.3000 & 0.3667 & 0.0000 & 0.4333 & 0.3667 \\
\hline & BD9 & & BD10 & BD11 & BD12 & & BD13 & BD14 \\
\hline BD1 & 0.8333 & & 0.0000 & 0.5000 & 0.5000 & & 0.8333 & 0.7444 \\
\hline BD2 & 0.4333 & & 0.7222 & 0.6778 & 0.7888 & & 0.7889 & 0.8333 \\
\hline BD3 & 0.3667 & & 0.0000 & 0.3000 & 0.4333 & & 0.3667 & 0.3000 \\
\hline BD4 & 0.0000 & & 0.0000 & 0.0000 & 0.3667 & & 0.3000 & 0.4333 \\
\hline BD5 & 0.7889 & & 0.8333 & 0.4333 & 0.4333 & & 0.4333 & 0.5667 \\
\hline BD6 & 0.5000 & & 0.0000 & 0.5000 & 0.5000 & & 0.6111 & 0.5000 \\
\hline BD7 & 0.5000 & & 0.0000 & 0.3000 & 0.4333 & & 0.5000 & 0.6333 \\
\hline BD8 & 0.3667 & & 0.0000 & 0.5000 & 0.5000 & & 0.3667 & 0.3667 \\
\hline BD9 & 0.0000 & & 0.0000 & 0.5000 & 0.4333 & & 0.5000 & 0.4333 \\
\hline BD10 & 0.8333 & & 0.0000 & 0.8333 & 0.6778 & & 0.7444 & 0.8333 \\
\hline BD11 & 0.0000 & & 0.0000 & 0.0000 & 0.5000 & & 0.3000 & 0.3667 \\
\hline BD12 & 0.3667 & & 0.0000 & 0.3000 & 0.0000 & & 0.3000 & 0.3000 \\
\hline BD13 & 0.3000 & & 0.0000 & 0.0000 & 0.3000 & & 0.0000 & 0.0000 \\
\hline BD14 & 0.3000 & & 0.0000 & 0.3000 & 0.3000 & & 0.3667 & 0.0000 \\
\hline
\end{tabular}


Table 6 Normalized average direct matrix

\begin{tabular}{|c|c|c|c|c|c|c|c|c|}
\hline & BD1 & BD2 & BD3 & BD4 & BD5 & BD6 & BD7 & BD8 \\
\hline BD1 & 0.0000 & 0.0847 & 0.0752 & 0.0609 & 0.0800 & 0.0847 & 0.0728 & 0.0537 \\
\hline BD2 & 0.0752 & 0.0000 & 0.0752 & 0.0609 & 0.0537 & 0.0000 & 0.0728 & 0.0895 \\
\hline BD3 & 0.0322 & 0.0000 & 0.0000 & 0.0680 & 0.0394 & 0.0000 & 0.0465 & 0.0465 \\
\hline BD4 & 0.0000 & 0.0000 & 0.0000 & 0.0000 & 0.0000 & 0.0000 & 0.0000 & 0.0000 \\
\hline BD5 & 0.0000 & 0.0680 & 0.0537 & 0.0609 & 0.0000 & 0.0000 & 0.0609 & 0.0609 \\
\hline BD6 & 0.0895 & 0.0776 & 0.0609 & 0.0537 & 0.0847 & 0.0000 & 0.0776 & 0.0465 \\
\hline BD7 & 0.0000 & 0.0000 & 0.0537 & 0.0609 & 0.0322 & 0.0000 & 0.0000 & 0.0716 \\
\hline BD8 & 0.0000 & 0.0000 & 0.0585 & 0.0609 & 0.0394 & 0.0000 & 0.0465 & 0.0000 \\
\hline BD9 & 0.0000 & 0.0000 & 0.0537 & 0.0537 & 0.0000 & 0.0000 & 0.0537 & 0.0537 \\
\hline BD10 & 0.0800 & 0.0895 & 0.0680 & 0.0776 & 0.0895 & 0.0000 & 0.0847 & 0.0895 \\
\hline BD11 & 0.0000 & 0.0000 & 0.0000 & 0.0752 & 0.0000 & 0.0000 & 0.0000 & 0.0465 \\
\hline BD12 & 0.0000 & 0.0000 & 0.0322 & 0.0322 & 0.0322 & 0.0000 & 0.0322 & 0.0322 \\
\hline BD13 & 0.0000 & 0.0000 & 0.0394 & 0.0752 & 0.0000 & 0.0000 & 0.0394 & 0.0000 \\
\hline \multirow[t]{2}{*}{ BD14 } & 0.0000 & 0.0394 & 0.0394 & 0.0322 & 0.0394 & 0.0000 & 0.0465 & 0.0394 \\
\hline & BD9 & & BD10 & BD11 & BD12 & & BD13 & BD14 \\
\hline BD1 & 0.0895 & & 0.0000 & 0.0537 & 0.0537 & & 0.0895 & 0.0800 \\
\hline BD2 & 0.0465 & & 0.0776 & 0.0728 & 0.0847 & & 0.0847 & 0.0895 \\
\hline BD3 & 0.0394 & & 0.0000 & 0.0322 & 0.0465 & & 0.0394 & 0.0322 \\
\hline BD4 & 0.0000 & & 0.0000 & 0.0000 & 0.0394 & & 0.0322 & 0.0465 \\
\hline BD5 & 0.0847 & & 0.0895 & 0.0465 & 0.0465 & & 0.0465 & 0.0609 \\
\hline BD6 & 0.0537 & & 0.0000 & 0.0537 & 0.0537 & & 0.0656 & 0.0537 \\
\hline BD7 & 0.0537 & & 0.0000 & 0.0322 & 0.0465 & & 0.0537 & 0.0680 \\
\hline BD8 & 0.0394 & & 0.0000 & 0.0537 & 0.0537 & & 0.0394 & 0.0394 \\
\hline BD9 & 0.0000 & & 0.0000 & 0.0537 & 0.0465 & & 0.0537 & 0.0465 \\
\hline BD10 & 0.0895 & & 0.0000 & 0.0895 & 0.0728 & & 0.0800 & 0.0895 \\
\hline BD11 & 0.0000 & & 0.0000 & 0.0000 & 0.0537 & & 0.0322 & 0.0394 \\
\hline BD12 & 0.0394 & & 0.0000 & 0.0322 & 0.0000 & & 0.0322 & 0.0322 \\
\hline BD13 & 0.0322 & & 0.0000 & 0.0000 & 0.0322 & & 0.0000 & 0.0000 \\
\hline BD14 & 0.0322 & & 0.0000 & 0.0322 & 0.0322 & & 0.0394 & 0.0000 \\
\hline
\end{tabular}

this NDRM is subjected to Eq. 6 to obtain the "total influence matrix (TIM)" as shown in Table 7. The "prominence" and "relation" value are also shown in Table 7, which has been used to obtain "influence relation map," as shown in Fig. 5. 
Table 7 Total influence matrix

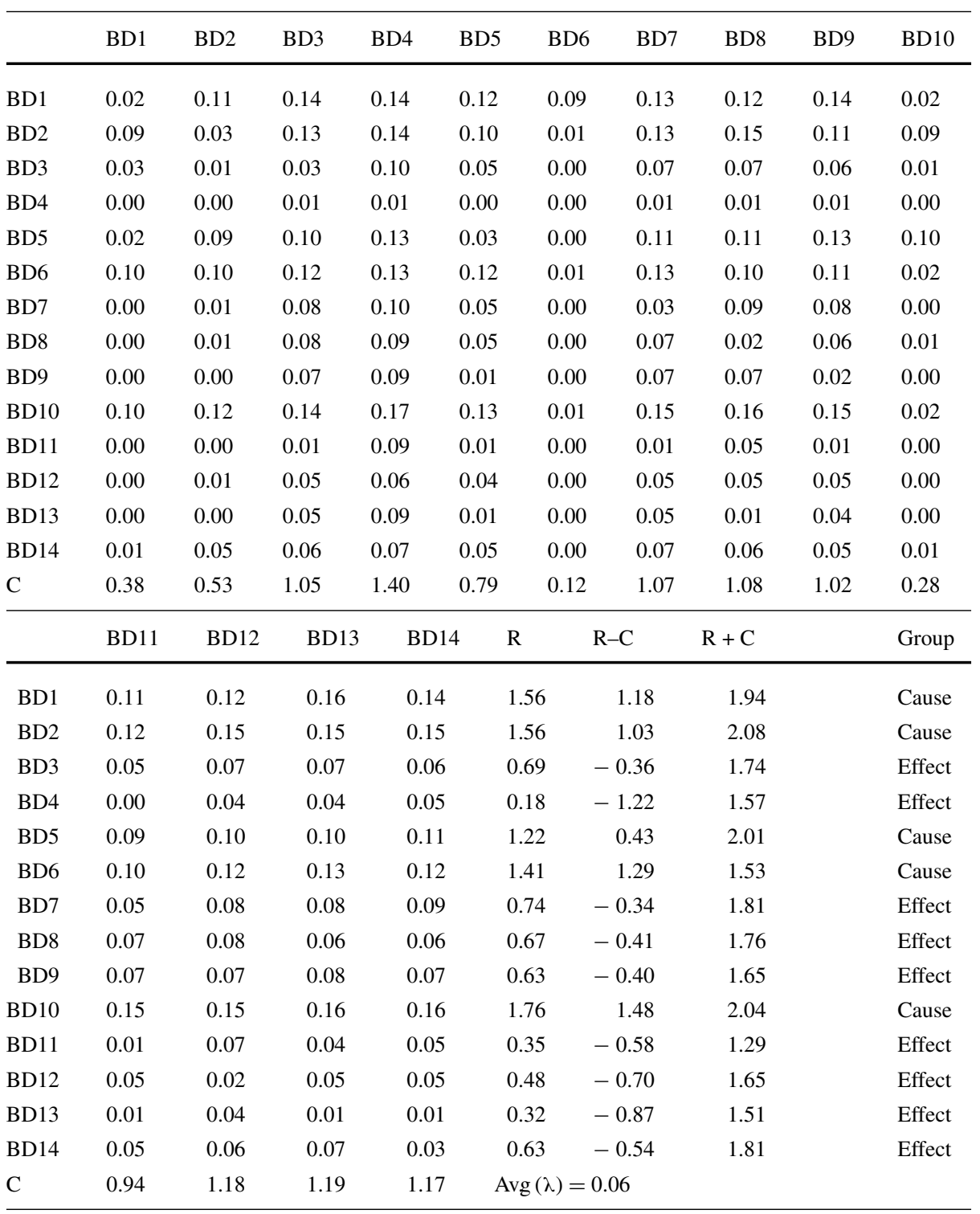

\section{Results and discussion}

\subsection{TISM results}

The TISM model aimed to get the hierarchy and interrelation between the identified construct to understand the interdependencies between them. Such information helps practitioners and 


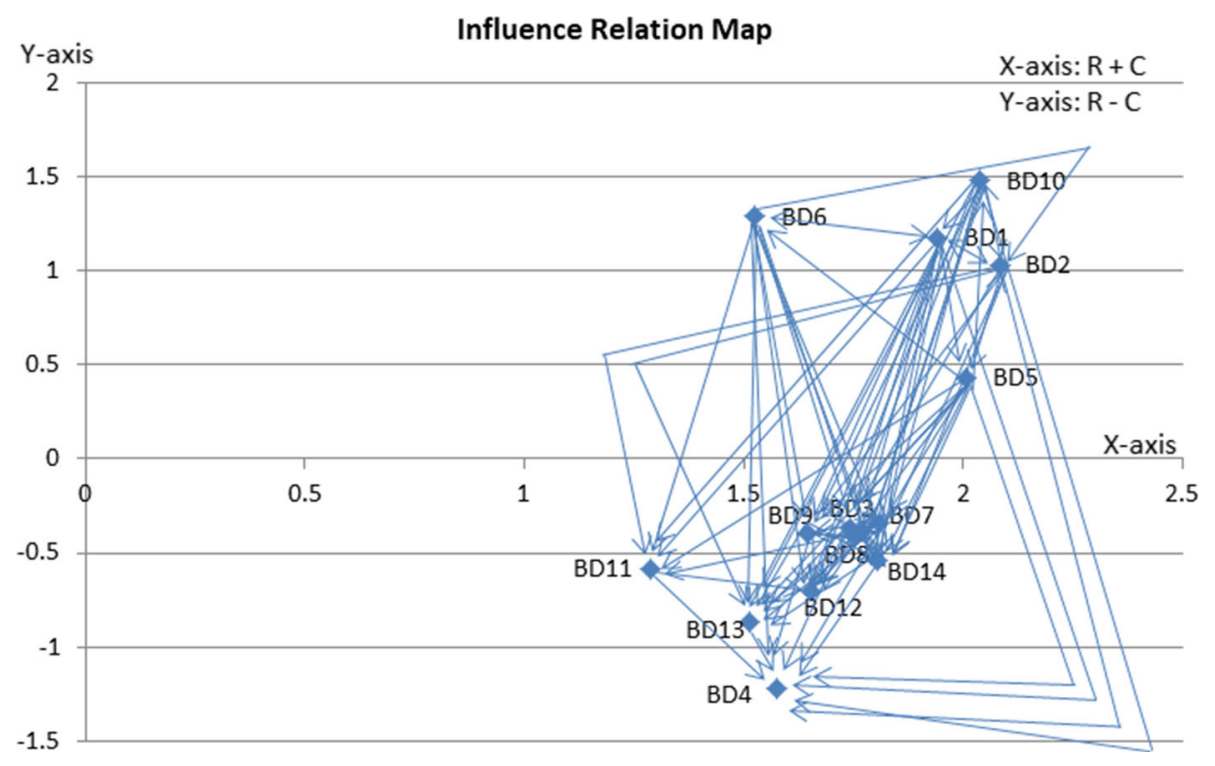

Fig. 5 Influence relation map

managers design their strategies for the successful adoption of a blockchain-based system to achieve sustainable food security. The TISM model presented in Fig. 3 is a five-level hierarchy, where each construct at a particular level drives another at the upper level. In our model, level one comprised of the constructs Settlement platform for agro-activities (BD13), Crowdfunding platform (BD12), and Ethical sharing platform amongst agro-stakeholder (BD4). Level two of hierarchy is comprised of Governance platform (BD14), Privacy (BD11), Secured and efficient transaction (BD8) and Trust in agri-business (BD3). These results are compliant with Kamble et al. (2020) where a similar level of influential power is assigned to these constructs. Level three of hierarchy is comprised of the constructs Provenance of agro-products (BD9) and Monitoring of agro-practices and process (BD7). The penultimate level consists of the constructs Certifications of agro-products and process (BD5) and Smart contract (BD2). These constructs are driven by the last level constructs, i.e., Traceability (BD1), Real-time information available to agro-stakeholders (i.e., information system) (BD6) and Decentralized and immutable database (BD10).

The construct at the bottom of the TISM model in Fig. 3 is the most significant driver for the adoption of the blockchain-based system in achieving sustainable food security. However, the Indian PDS face problems such as food loss, food wastages, food frauds and procurement delays (Kaur, 2021). The PDS data are highly mutated by intermediaries to obtain ill-benefits from the system. The experts of this study were well aware of these circumstances. They were also in agreement with the findings that blockchain-based traceability (BD1) could be used to track the mischievous party, and consequential actions can be taken as the blockchain-based database is immutable and decentralized (BD10) and can be inspected openly. For example, the Spices Board India has signed an MOU with UNDP India's Accelerator Lab to design an interface working on blockchain to track and maintain transparency in spices trade (Spices Board inks deal with UNDP to develop blockchain-powered traceability interface, 2021). 
Furthermore, integration of blockchain with PDS helps to improve the PDS efficiency to ensure food security (Kumar, 2021). The blockchain-based system also provides real-time information to agro-stakeholders (BD6) and may act as a perfect information system to provide for example weather forecast information or produce market price evolution. Thus, traceability, decentralized and immutable databases and real-time information availability to agro-stakeholders are primary drivers for the adoption of a blockchain-based system to achieve sustainable food security.

Furthermore, decentralized and immutable database leads to the smart contract (BD2), while real-time information availability (BD6) and traceability ensure the certification of agro-products and processes (BD5). Both smart contracts and certification improve efficient monitoring of agro-practices and processes (BD7) and thus encourage provenance verification of agro-products (BD9). Generally, Indian farmers have tiny farms that may be shared to reap better benefits. The sharing mechanisms could be embedded with the smart contractbased system. However, the experts of this study are skeptical about the compliance in sharing. Moreover, smart contracts encourage efficient mechanisms for crop insurance and buying/selling agro commodities.

In addition, real-time information availability and certification help blockchain act as a governance platform (BD14) to recode the data. The experts involved in this study stated that blockchain-based governance, especially in documentation such as land registration and farm ownership, would play a key role in improving the ASC procedures. On a similar line, Thakur et al. (2020) have discussed the idea of land registration on the blockchainbased system in the Indian context. Furthermore, the pilot project for land registration has been implemented in some Indian states such as Maharashtra, Uttar Pradesh and Haryana (Government Plans to Link e-Courts With Land Records to Ease Property Registration, 2021). The experts agreed that such a mechanism would be authentic, tamper-proof, and would provide absolute ownership rights. Another example of governance is the use of blockchain in subsidy distribution with the right quantity to the right person through preventing any forgery. Furthermore, contract farming would result in better agreement between farmers and corporates.

Ensuring traceability in end-to-end supply chain results in the creation of trust in business (BD3). Further blockchain-based monitoring helps obtain secure and efficient transactions (BD8) as the blockchain data is immutable and can be checked by all connected nodes of the system. In addition, the data on the blockchain-based system is cryptographically secured, which leads to privacy (BD11) and better maintenance of governance records (BD14). Trust in business encourages ethical sharing amongst agro-stakeholders (BD4). It also brings investors to crowdsourcing as the blockchain-based systems are trustworthy and can facilitate the settlement of any dispute in an ethical manner. Moreover, secured transactions and governance fosters crowdsourcing (B12), settlements (BD13) and increases ethical sharing (BD4). The settlement of any dispute is enabled by the blockchain-based system since a smart contract secures collective agreement data. In the case of crop loss, blockchain-based insurance would be a particularly viable solution. Another aspect where this study's experts showed their concern was the ease of use and behavioral impact on the ASC stakeholders. This finding is in line with the survey conducted by Queiroz and Wamba (2019) who report that the individuals in India believe that adopting blockchain would result in performance enhancement. 


\subsection{Fuzzy MICMAC results}

The blockchain-based drivers for sustainable food security were clustered into four groups as depicted in Fig. 4:

1. Autonomous: These types of constructs are disconnected from the observed system and have low dependence and driving power. In our case, no construct (i.e., drivers) was reported in this category.

2. Dependence: These types of constructs have relatively low driving power but are highly dependent on other constructs. Furthermore, these types of the construct are found on the top level of the hierarchy as other constructs drive them. These constructs are often considered as performance-oriented factors. In our case, "trust in business (BD3), ethical sharing amongst agro-stakeholders (BD4), monitoring of agro-practices and processes (BD7), secured and efficient transactions (BD8), provenance of agro-products (BD9), privacy (BD11), crowdsourcing platform (BD12), settlement platform (BD13) and governance platform (BD14)" falls independence category.

3. Linkages: These types of the construct are highly sensitive as they have very high driving as well as dependence power. These constructs are not easy to handle due to their nature and hence need extra care and effort to manage. In our case, no construct (i.e., drivers) was reported in this category.

4. Driving: These constructs have prime importance as they have very high driving power and have the least dependencies on others. These constructs help to achieve other constructs. In our case, "traceability (BD1), smart contract (BD2), certification of agro products and processes (BD5), real-time information available to agro-stakeholders (BD6), decentralized and immutable databases (BD10)" falls under the driving category.

\subsection{Fuzzy-DEMATEL results}

Fuzzy DEMATEL can determine the intensity of the interrelationships between constructs, which is missing in the TISM model, and it helps to evaluate the strength of importance to be given to a particular construct. It also segregates the construct into cause and effect groups. Causal group factors have a high potential to drive other constructs while the effect group's constructs depend on causal factors. The Fuzzy DEMATEL analysis showed that "facilitates traceability (BD1), smart contract (BD2), certification of agro products and processes (BD5), real-time information available to agro-stakeholders (BD6), decentralized and immutable databases (BD10)" are causal constructs. The effect group constitutes of constructs like "trust in business (BD3), ethical sharing amongst agro-stakeholders (BD4), monitoring of agro-practices and processes (BD7), secured and efficient transactions (BD8), provenance of agro-products (BD9), privacy (BD11), crowdsourcing platform (BD12), settlement platform (BD13) and governance platform (BD14)." The results of the Fuzzy DEMATEL analysis are impressive as it verifies the results obtained from Fuzzy MICMAC. The construct in the driving category of Fuzzy MICMAC is obtained as a causal construct in Fuzzy DEMATEL, which seems logical as the construct which has high driving potential would help to achieve other constructs. The direct and indirect influence of all constructs is shown in Table 7. However, to show the significant influence, we have used a threshold value, i.e. an average of elements in "total influence matrix," as pointed out in the work of Gardas et al. (2019b) and Yadav et al. (2020). The threshold value, in our case, was 0.0622 . The influence value, which is more than this threshold value, was considered as the most significant relationship, and the same is shown on the influence relation map (see Fig. 5). 


\subsection{Managerial Implications}

The incorporation of the blockchain-based system in the agro-supply chain could help to achieve sustainable food security and simultaneously could be a significant economic booster for developing countries like India. Each blockchain driver identified in this work helps to achieve sustainable food security in certain way. The results of the study provide several insights for the agro-organization's managers and policymakers to enable sustainable food security:

1. Use of blockchain to enable traceability and real-time information availability to maintain sustainable food compliance

Traceability is a big USP for a blockchain based system. Furthermore, IoT device can be embedded with blockchain platform to provide real-time information and simultaneously can build a full proof system. In addition, as there is a high demand of organic products and requirement of operating sustainably in various agro-activities, blockchain basedtraceability is well adapted to certify products origins and the processes in which they get involved. TraceX Technologies is a start-up using blockchain technology to track maize value chain for 1000 farmers in the Belgaum district of Karnataka (Cisco \& Social Alpha launch 'Krishi Mangal'; support five high-impact agritech startups, 2021). Moreover, in case of any attempt of fraud, a blockchain-based system could generate warnings, so that precautionary measures can be taken. Through such system, the compliance related to sustainable food security can be maintained.

2. Use of blockchain in food security governance and monitoring of agro-activities

The governance and monitoring of various agro-processes plays an important role in enabling food security. The benefits of government schemes do not reach the needy due to corruption, which can be monitored by implementing adapted schemes on blockchain platforms. For example, the Indian PDS should be embedded with blockchain to improve its efficiency and ensure food security (Kumar, 2021). Furthermore, few Indian states such as Maharashtra, Haryana and Uttar Pradesh have successfully run the pilot project to link the land records and registration databases with e-courts. Furthermore, the blockchain based system could be useful for maintaining land records and land ownership, which are the main causes for disputes in India (Thakur et al., 2020).

3. Smart-contract based settlement and sharing platform for achieving sustainable food security in environmental and social aspect

The smart contract mechanism may be used for crop insurance, which will secure farms in case of untoward situations. Indian farmers mostly have tiny farms that may be shared to reap better benefits, and this sharing mechanism could be embedded with the smart contract-based mechanisms. Therefore, disputes in the agreement can be settled through smart contracts mechanisms.

4. Blockchain as a medium for safe, secure and efficient agri-business system for achieving sustainable food security in economic aspect

The study's findings also emphasize that blockchain maintains secure transactions and takes care of privacy, thus building the trust amongst agro-stakeholders for efficient agro-business. Trust in the system could solve capital investment in agriculture through crowdfunding as the investors can feel more secure regarding their invested money in the blockchain environment. For example, the government of Maharashtra is set to use blockchain for agriculture marketing (Maharashtra to use blockchain technology in agriculture marketing $\&$ vehicle registration, 2019). 
In addition, 50\% of Indian states are involved in blockchain projects in some form or another (NASSCOM, 2019). However, the initial investment in technology and skill requirement for training to use blockchain based system are still challenging issues (Choi, 2020). Furthermore, the government may incentivize the use of blockchain technology and simultaneously create awareness about its benefits its. In addition, another challenge is to make blockchain technology interoperable with existing ASC infrastructure. Whereas technical challenges still exist to make blockchain technology as scalable to wide variety of Indian consumers.

\subsection{Scientific and theoretical contributions}

This study contributes to the literature in various ways. At first, several new drivers of the blockchain to ensure sustainable food security are identified, such as ethical sharing platform amongst agro-stakeholder, monitoring of agro-practices and processes, crowdsourcing platform, settlement platform, and governance platform. Secondly, the results of the study is summarized in form of insights for ASC managers, practitioners and policymakers to frame suitable strategies for making the blockchain adoption to be used for sustainable food security. For example, operationalization of Indian PDS on blockchain based system would prevent food fraud, food loss and corruption. In addition, food security programs and beneficiaries schemes should be integrated with blockchain to ensure its reachability to the right person. Furthermore, to position the findings of this study in the literature, comparison is made with the results of Queiroz and Wamba (2019) and Kamble et al. (2020). Queiroz and Wamba (2019) reported that performance expectancy, social influence, and trust drive the behavior of blockchain adoption in the Indian context, whereas trust is also supported in our study. Other important enablers of blockchain adoption like traceability, immutability, provenance, privacy, secured and efficient transactions, and their influential power reported in the work of Kamble et al. (2020) are in line with our work. On the other side, our study position smart contracts and decentralized databases as highly significant drivers, this is different from the literature perspective. In fact, the experts involved in this study highlight that smart contracts are revolutionizing the way contract will done. Moreover, smart contracts have the potential to bring many reformations in contract farming, farm sharing, smart financing and loan engagement, while decentralized databases will support the smart contract in backend solution. In addition to this, new drivers identified in this study through fieldwork emphasizes on the need to take initiatives for adoption of blockchain in ASC.

\section{Conclusion}

The study investigated the blockchain adoption drivers to achieve sustainable food security in the Indian context. A total of 14 drivers were identified through an extensive literature search and the opinions of domain experts from industries, academia, and agro-stakeholders. The identified drivers were modeled using an integrated TISM Fuzzy-DEMATEL approach where TISM evaluated the interrelationship between identified constructs and built their hierarchy while Fuzzy-DEMATEL investigated the intensity of relationship amongst them. Fuzzy MICMAC was utilized to evaluate the driving and dependence power of each driver so that policymakers could pay proper attention to them for the successful adoption of the blockchain-based system. The findings of the study revealed that traceability (BD1), real-time 
information available to agro-stakeholders (i.e., information system) (BD6), and decentralized and immutable database (BD10) were the most significant drivers for blockchain adoption. The moderately significant drivers include "smart contracts (BD2), certification of agro products and processes (BD5), monitoring of agro-practices and processes (BD7), and provenance of agro-products (BD9). The least significant drivers include "trust in business (BD3), ethical sharing amongst agro-stakeholders (BD4), secured and efficient transactions (BD8), privacy (BD11), crowdsourcing platform (BD12), settlement platform (BD13) and governance platform (BD14)." These factors were investigated for causal-interrelationship.

The contribution of the work is threefold; (i) this work identifies several new blockchain drivers such as ethical sharing amongst agro-stakeholders (BD4), crowdsourcing platform (BD12), settlement platform (BD13) and governance platform (BD14), which are mainly performance-oriented drivers, and monitoring of agro-practices and processes (BD7) was moderately significant drivers (ii) this study makes use of an integrated MCDM approach by combining TISM and Fuzzy DEMATEL, and (iii) this study opens the doors for strategy formulation regarding blockchain adoption to improve sustainable food security. The findings of the study may be utilized by policymakers, concerned government and private agencies, agro-stakeholders, and non-government organizations (NGOs) to prepare suitable strategies for increasing the blockchain adoption rate.

The study was limited to the Indian context and involving Indian experts. Moreover, the low blockchain related expertise of the experts involved in the Delphi study is a limiting factor for this work. Therefore, the findings cannot be generalized to other regions and developed nations. An addition limitation concerns Blockchain diffusion issues that were not discussed in this study, which may be a concern for some ASC stakeholders like farmers and intermediaries. In the future, the impact assessment of blockchain adoption should be investigated for economic viability using MCDM methods such as the Fuzzy Evidential Reasoning Approach.

Funding Open access funding provided by University of Applied Sciences and Arts Western Switzerland (HES-SO).

Open Access This article is licensed under a Creative Commons Attribution 4.0 International License, which permits use, sharing, adaptation, distribution and reproduction in any medium or format, as long as you give appropriate credit to the original author(s) and the source, provide a link to the Creative Commons licence, and indicate if changes were made. The images or other third party material in this article are included in the article's Creative Commons licence, unless indicated otherwise in a credit line to the material. If material is not included in the article's Creative Commons licence and your intended use is not permitted by statutory regulation or exceeds the permitted use, you will need to obtain permission directly from the copyright holder. To view a copy of this licence, visit http://creativecommons.org/licenses/by/4.0/.

\section{Appendix-A}

\section{See Table 8}




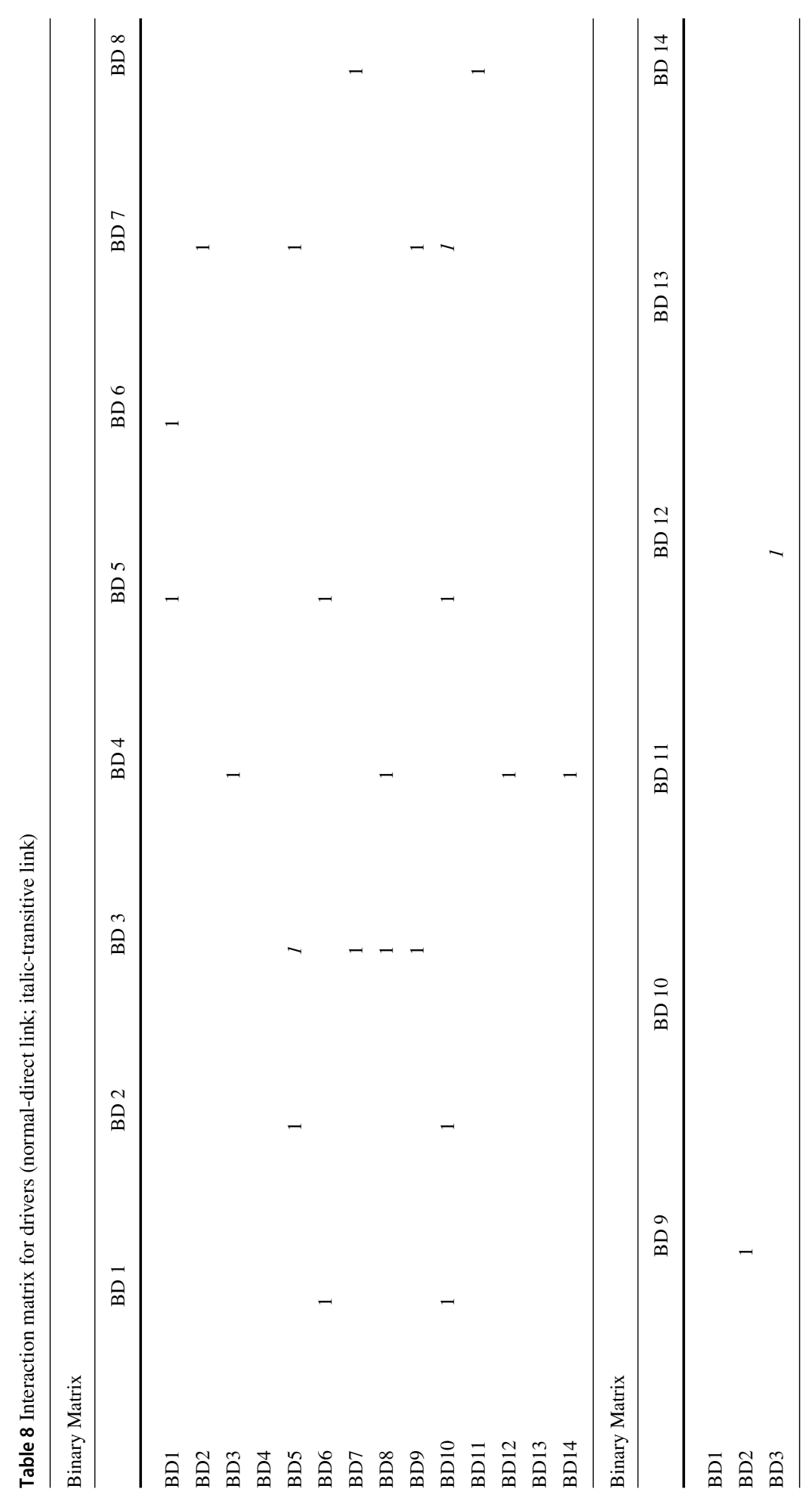




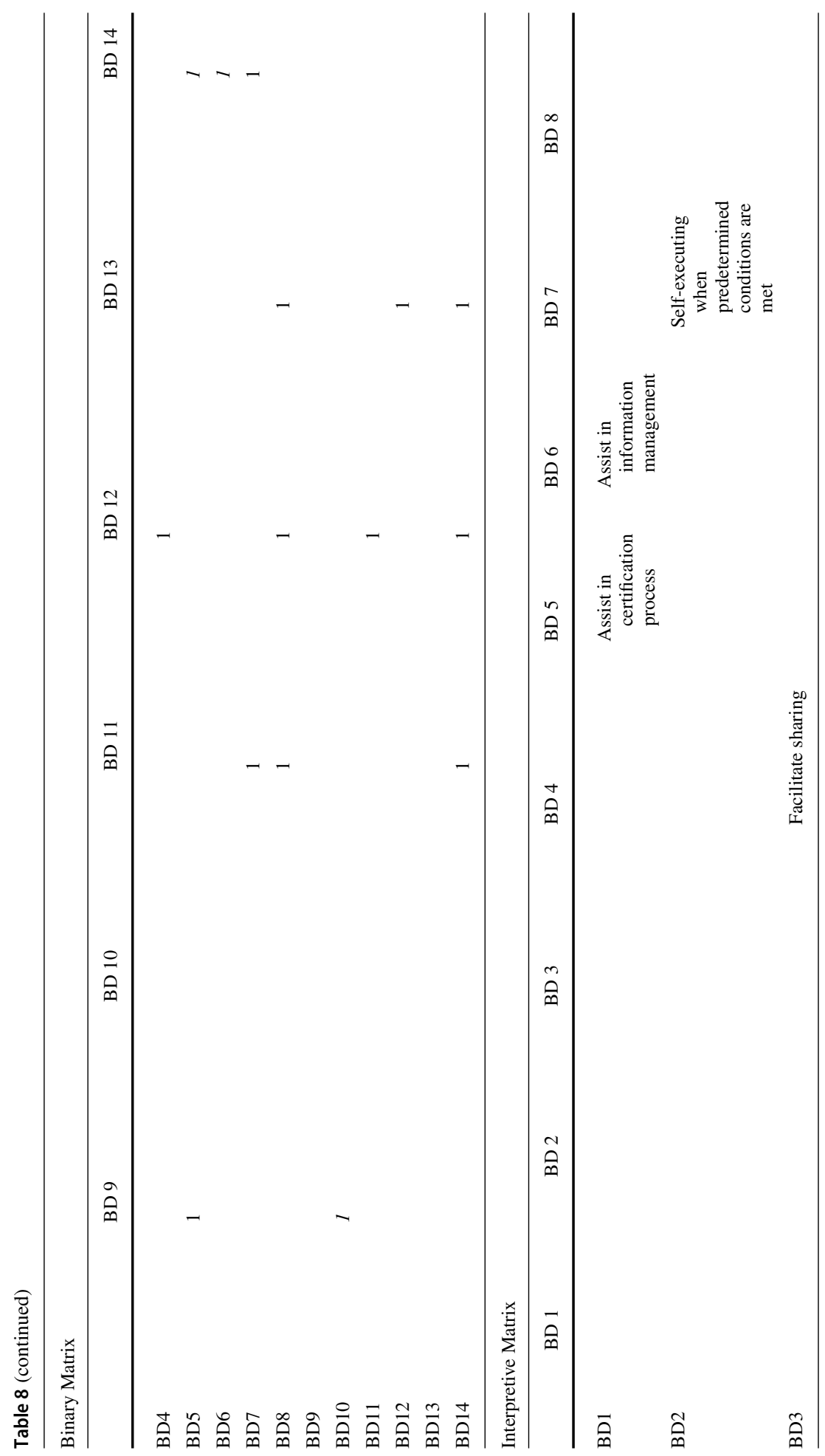




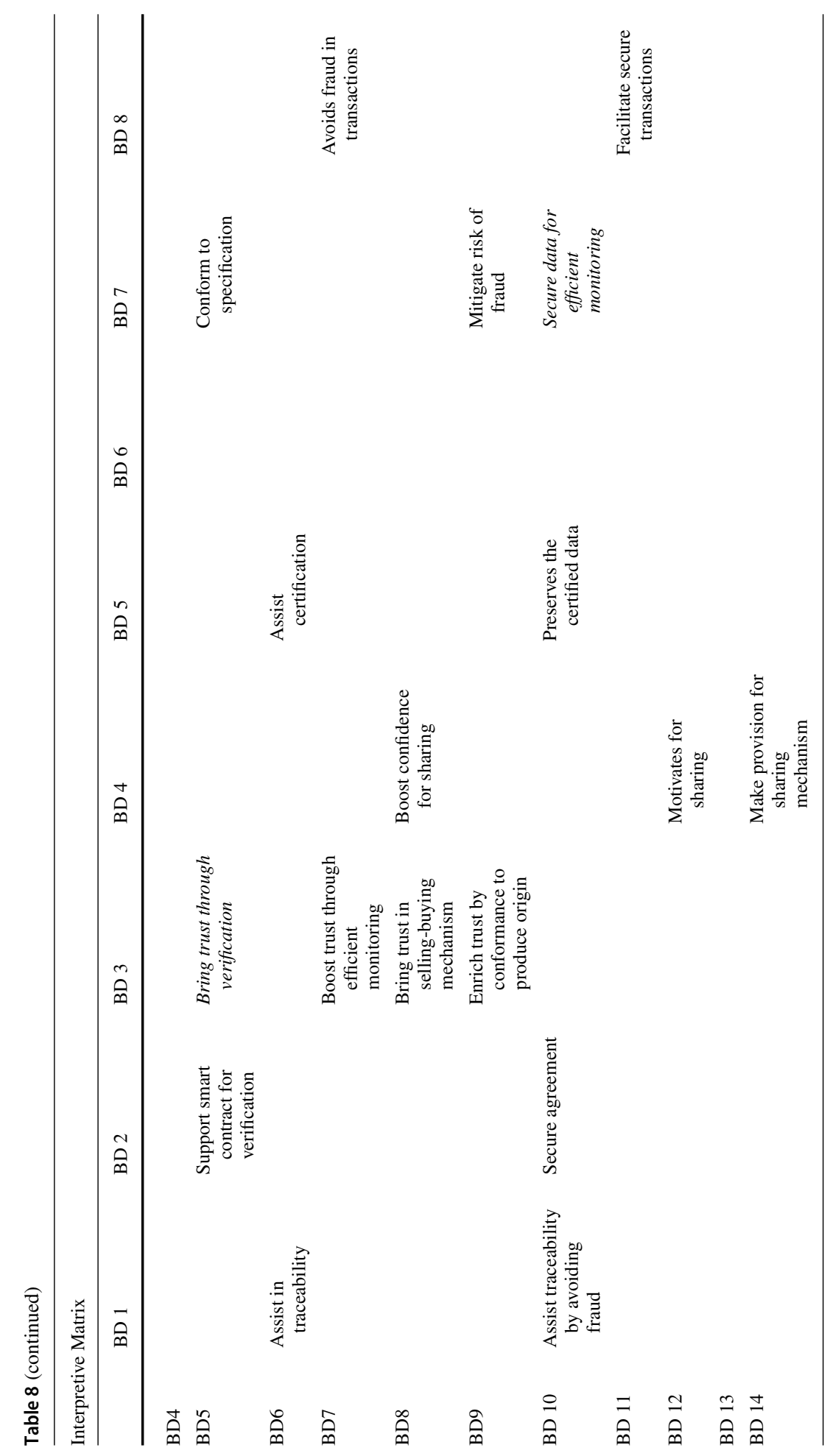




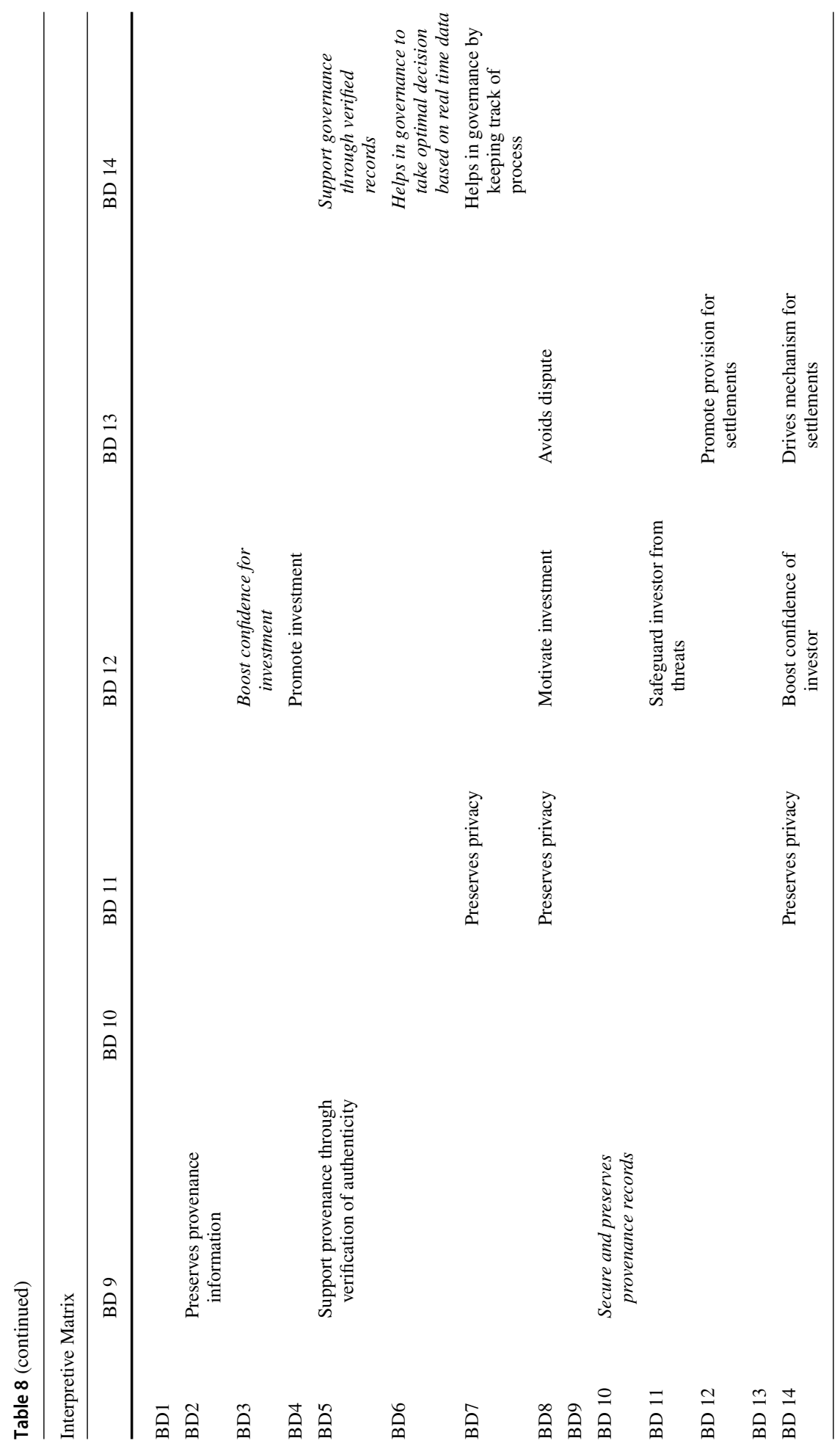




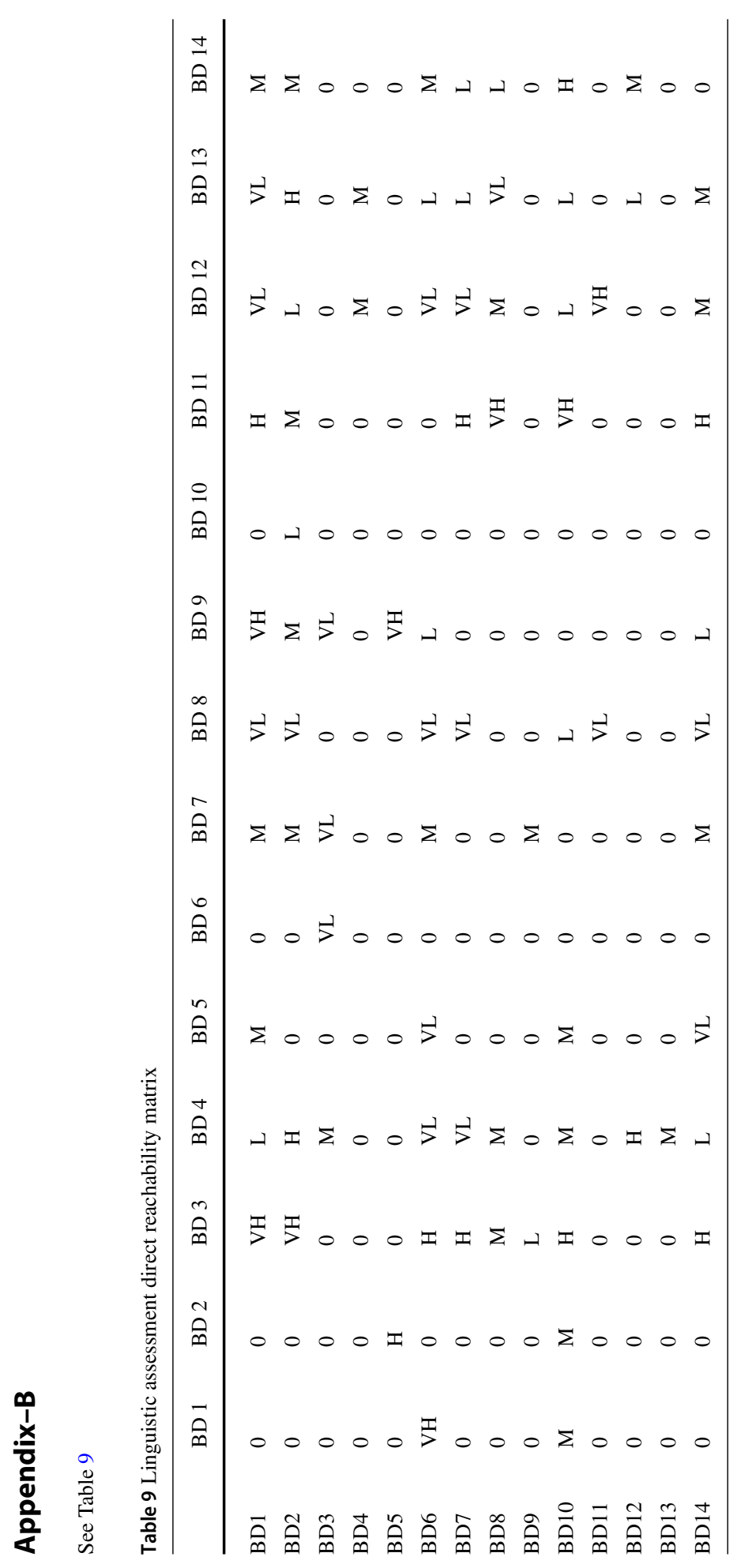


Appendix-C

See Table 10

Table 10 Defuzzified direct reachability matrix

\begin{tabular}{|c|c|c|c|c|c|c|c|c|}
\hline & BD 1 & BD 2 & BD 3 & BD 4 & BD 5 & BD 6 & BD 7 & BD 8 \\
\hline BD1 & 0 & 0 & 0.8667 & 0.3 & 0.5 & 0 & 0.5 & 0.1333 \\
\hline BD2 & 0 & 0 & 0.8667 & 0.7 & 0 & 0 & 0.5 & 0.1333 \\
\hline BD3 & 0 & 0 & 0 & 0.5 & 0 & 0.1333 & 0.1333 & 0 \\
\hline BD4 & 0 & 0 & 0 & 0 & 0 & 0 & 0 & 0 \\
\hline BD5 & 0 & 0.7 & 0 & 0 & 0 & 0 & 0 & 0 \\
\hline BD6 & 0.8667 & 0 & 0.7 & 0.1333 & 0.1333 & 0 & 0.5 & 0.1333 \\
\hline BD7 & 0 & 0 & 0.7 & 0.1333 & 0 & 0 & 0 & 0.1333 \\
\hline BD8 & 0 & 0 & 0.5 & 0.5 & 0 & 0 & 0 & 0 \\
\hline BD9 & 0 & 0 & 0.3 & 0 & 0 & 0 & 0.5 & 0 \\
\hline BD10 & 0.5 & 0.5 & 0.7 & 0.5 & 0.5 & 0 & 0 & 0.3 \\
\hline BD11 & 0 & 0 & 0 & 0 & 0 & 0 & 0 & 0.1333 \\
\hline BD12 & 0 & 0 & 0 & 0.7 & 0 & 0 & 0 & 0 \\
\hline BD13 & 0 & 0 & 0 & 0.5 & 0 & 0 & 0 & 0 \\
\hline \multirow[t]{2}{*}{ BD14 } & 0 & 0 & 0.7 & 0.3 & 0.1333 & 0 & 0.5 & 0.1333 \\
\hline & \multicolumn{2}{|l|}{ BD 9} & BD 10 & BD 11 & \multicolumn{2}{|l|}{ BD 12} & BD 13 & BD 14 \\
\hline BD1 & \multicolumn{2}{|l|}{0.8667} & 0 & 0.7 & \multicolumn{2}{|l|}{0.1333} & 0.1333 & 0.5 \\
\hline BD2 & \multicolumn{2}{|l|}{0.3} & 0.3 & 0.5 & \multicolumn{2}{|l|}{0.3} & 0.7 & 0.5 \\
\hline BD3 & \multicolumn{2}{|l|}{0.1333} & 0 & 0 & \multicolumn{2}{|l|}{0} & 0 & 0 \\
\hline BD4 & \multicolumn{2}{|l|}{0} & 0 & 0 & \multicolumn{2}{|l|}{0.5} & 0.5 & 0 \\
\hline BD5 & \multicolumn{2}{|l|}{0.8667} & 0 & 0 & \multicolumn{2}{|l|}{0} & 0 & 0 \\
\hline BD6 & \multicolumn{2}{|l|}{0.3} & 0 & 0 & \multicolumn{2}{|l|}{0.1333} & 0.3 & 0.5 \\
\hline BD7 & 0 & & 0 & 0.7 & \multicolumn{2}{|l|}{0.1333} & 0.3 & 0.3 \\
\hline BD8 & 0 & & 0 & 0.8667 & \multicolumn{2}{|l|}{0.5} & 0.1333 & 0.3 \\
\hline BD9 & 0 & & 0 & 0 & \multicolumn{2}{|l|}{0} & 0 & 0 \\
\hline BD10 & 0 & & 0 & 0.8667 & \multicolumn{2}{|l|}{0.3} & 0.3 & 0.7 \\
\hline BD11 & 0 & & 0 & 0 & \multicolumn{2}{|l|}{0.8667} & 0 & 0 \\
\hline BD12 & 0 & & 0 & 0 & \multicolumn{2}{|l|}{0} & 0.3 & 0.5 \\
\hline BD13 & 0 & & 0 & 0 & \multicolumn{2}{|l|}{0} & 0 & 0 \\
\hline BD14 & 0.3 & & 0 & 0.7 & \multicolumn{2}{|l|}{0.5} & 0.5 & 0 \\
\hline
\end{tabular}




\section{Appendix-D}

See Table 11

Table 11 Fuzzy MICMAC-stabilized matrix

\begin{tabular}{|c|c|c|c|c|c|c|c|c|}
\hline & BD 1 & BD 2 & BD 3 & BD 4 & BD 5 & BD 6 & BD 7 & BD 8 \\
\hline BD1 & 0 & 0 & 0.8667 & 0.3 & 0.5 & 0 & 0.5 & 0.1333 \\
\hline BD2 & 0 & 0 & 0.8667 & 0.7 & 0 & 0 & 0.5 & 0.1333 \\
\hline BD3 & 0 & 0 & 0 & 0.5 & 0 & 0.1333 & 0.1333 & 0 \\
\hline BD4 & 0 & 0 & 0 & 0 & 0 & 0 & 0 & 0 \\
\hline BD5 & 0 & 0.7 & 0 & 0 & 0 & 0 & 0 & 0 \\
\hline BD6 & 0.8667 & 0 & 0.7 & 0.1333 & 0.1333 & 0 & 0.5 & 0.1333 \\
\hline BD7 & 0 & 0 & 0.7 & 0.1333 & 0 & 0 & 0 & 0.1333 \\
\hline BD8 & 0 & 0 & 0.5 & 0.5 & 0 & 0 & 0 & 0 \\
\hline BD9 & 0 & 0 & 0.3 & 0 & 0 & 0 & 0.5 & 0 \\
\hline BD10 & 0.5 & 0.5 & 0.7 & 0.5 & 0.5 & 0 & 0 & 0.3 \\
\hline BD11 & 0 & 0 & 0 & 0 & 0 & 0 & 0 & 0.1333 \\
\hline BD12 & 0 & 0 & 0 & 0.7 & 0 & 0 & 0 & 0 \\
\hline BD13 & 0 & 0 & 0 & 0.5 & 0 & 0 & 0 & 0 \\
\hline \multirow[t]{2}{*}{ BD14 } & 0 & 0 & 0.7 & 0.3 & 0.1333 & 0 & 0.5 & 0.1333 \\
\hline & \multicolumn{2}{|l|}{ BD 9} & BD 10 & BD 11 & \multicolumn{2}{|l|}{ BD 12} & BD 13 & BD 14 \\
\hline BD1 & \multicolumn{2}{|l|}{0.8667} & 0 & 0.7 & \multicolumn{2}{|l|}{0.1333} & 0.1333 & 0.5 \\
\hline BD2 & \multicolumn{2}{|l|}{0.3} & 0.3 & 0.5 & \multicolumn{2}{|l|}{0.3} & 0.7 & 0.5 \\
\hline BD3 & \multicolumn{2}{|l|}{0.1333} & 0 & 0 & \multicolumn{2}{|l|}{0} & 0 & 0 \\
\hline BD4 & \multicolumn{2}{|l|}{0} & 0 & 0 & \multicolumn{2}{|l|}{0.5} & 0.5 & 0 \\
\hline BD5 & \multicolumn{2}{|l|}{0.8667} & 0 & 0 & \multicolumn{2}{|l|}{0} & 0 & 0 \\
\hline BD6 & \multicolumn{2}{|l|}{0.3} & 0 & 0 & \multicolumn{2}{|l|}{0.1333} & 0.3 & 0.5 \\
\hline BD7 & \multicolumn{2}{|l|}{0} & 0 & 0.7 & \multicolumn{2}{|l|}{0.1333} & 0.3 & 0.3 \\
\hline BD8 & \multicolumn{2}{|l|}{0} & 0 & 0.8667 & \multicolumn{2}{|l|}{0.5} & 0.1333 & 0.3 \\
\hline BD9 & \multicolumn{2}{|l|}{0} & 0 & 0 & \multicolumn{2}{|l|}{0} & 0 & 0 \\
\hline BD10 & \multicolumn{2}{|l|}{0} & 0 & 0.8667 & \multicolumn{2}{|l|}{0.3} & 0.3 & 0.7 \\
\hline BD11 & \multicolumn{2}{|l|}{0} & 0 & 0 & \multicolumn{2}{|l|}{0.8667} & 0 & 0 \\
\hline BD12 & \multicolumn{2}{|l|}{0} & 0 & 0 & \multicolumn{2}{|l|}{0} & 0.3 & 0.5 \\
\hline BD13 & \multicolumn{2}{|l|}{0} & 0 & 0 & \multicolumn{2}{|l|}{0} & 0 & 0 \\
\hline BD14 & \multicolumn{2}{|l|}{0.3} & 0 & 0.7 & 0.5 & & 0.5 & 0 \\
\hline
\end{tabular}




\section{References}

Antonucci, F., Figorilli, S., Costa, C., Pallottino, F., Raso, L., \& Menesatti, P. (2019). A review on blockchain applications in the agri-food sector. Journal of the Science of Food and Agriculture, 99(14), 6129-6138.

Behnke, K., \& Janssen, M. F. W. H. A. (2020). Boundary conditions for traceability in food supply chains using blockchain technology. International Journal of Information Management, 52, 101969.

Bhattacharya A. (2018). Blockchain is helping build a new Indian city, but it's no cure for corruption. https:// tinyurl.com/jhmqqo4f . Accessed on February 22nd 2021

Bhosale, V. A., \& Kant, R. (2016). An integrated ISM fuzzy MICMAC approach for modelling the supply chain knowledge flow enablers. International Journal of Production Research, 54(24), 7374-7399.

Brahmanand, P. S., Kumar, A., Ghosh, S., Chowdhury, S. R., Singandhupe, R. B., Singh, R., Behera, M. S. (2013). Challenges to food security in India. Current Science, 841-846.

Campbell, B. M., Vermeulen, S. J., Aggarwal, P. K., Corner-Dolloff, C., Girvetz, E., Loboguerrero, A. M., \& Wollenberg, E. (2016). Reducing risks to food security from climate change. Global Food Security, 11, 34-43.

Chang, Y., Iakovou, E., \& Shi, W. (2019a). Blockchain in global supply chains and cross border trade: A critical synthesis of the state-of-the-art, challenges and opportunities. International Journal of Production Research, 58(7), 2082-2099.

Chang, S. E., Chen, Y. C., \& Wu, T. C. (2019b). Exploring blockchain technology in international trade. Industrial Management and Data Systems, 119(8), 1712-1733.

Choi, T. M. (2020). Supply chain financing using blockchain: Impacts on supply chains selling fashionable products. Annals of Operations Research. https://doi.org/10.1007/s10479-020-03615-7

Cisco and Social Alpha launch 'Krishi Mangal'; support five high-impact agritech startups. (2021). https:// tinyurl.com/b9xyn6zs. Last accessed on 16/07/2021.

Clohessy, T., \& Acton, T. (2019). Investigating the influence of organizational factors on blockchain adoption. Industrial Management and Data Systems, 119(7), 1457-1491.

Cole, R., Stevenson, M., \& Aitken, J. (2019). Blockchain technology: Implications for operations and supply chain management. Supply Chain Management: An International Journal, 24(4), 469-483.

Dame, J., \& Nüsser, M. (2011). Food security in high mountain regions: Agricultural production and the impact of food subsidies in Ladakh, Northern India. Food Security, 3(2), 179-194.

Dev, S. M., \& Sharma, A. N. (2010). Food security in India: performance, challenges and policies. New Delhi: Oxfam India.

Dolgui, A., Ivanov, D., Potryasaev, S., Sokolov, B., Ivanova, M., \& Werner, F. (2020). Blockchain-oriented dynamic modelling of smart contract design and execution in the supply chain. International Journal of Production Research, 58(7), 2184-2199.

Fan, Z. P., Wu, X. Y., \& Cao, B. B. (2020). Considering the traceability awareness of consumers: Should the supply chain adopt the blockchain technology? Annals of Operations Research. https://doi.org/10.1007/ s10479-020-03729-y

FAO (1996), "Rome declaration on World Food Security and world food summit plan of action", World Food Summit, Rome, 13-17 November. http://www.fao.org/3/w3613e/w3613e00.htm (accessed on September 2nd 2020)

Galvez, J. F., Mejuto, J. C., \& Simal-Gandara, J. (2018). Future challenges on the use of blockchain for food traceability analysis. TrAC Trends in Analytical Chemistry, 107, 222-232.

Gabus, A., \& Fontela, E. (1972). World problems, an invitation to further thought within the framework of DEMATEL. Battelle Geneva Research Center, Geneva, Switzerland, 1-8.

Gardas, B. B., Raut, R. D., \& Narkhede, B. (2018). Evaluating critical causal factors for post-harvest losses (PHL) in the fruit and vegetables supply chain in India using the DEMATEL approach. Journal of Cleaner Production, 199, 47-61.

Gardas, B. B., Mangla, S. K., Raut, R. D., Narkhede, B., \& Luthra, S. (2019a). Green talent management to unlock sustainability in the oil and gas sector. Journal of Cleaner Production, 229, 850-862.

Gardas, B. B., Raut, R. D., Cheikhrouhou, N., \& Narkhede, B. E. (2019b). A hybrid decision support system for analyzing challenges of the agricultural supply chain. Sustainable Production and Consumption, 18, 19-32.

Ge, L., Brewster, C., Spek, J., Smeenk, A., Top, J., van Diepen, F., de Wildt, M. D. R. (2017). Blockchain for agriculture and food: Findings from the pilot study (No. 2017-112). Wageningen Economic Research.

George, P. S. (1999). Some reflections on food security in India. Indian Journal of Agricultural Economics, 54(4), 465-489.

George, R. V., Harsh, H. O., Ray, P., \& Babu, A. K. (2019). Food quality traceability prototype for restaurants using blockchain and food quality data index. Journal of Cleaner Production, 240, 118021. 
Government Plans to Link e-Courts with Land Records to Ease Property Registration. (2021). https://tinyurl. com/f4b5e2w7. Last accessed on 16/07/2021.

Gustavsson, J., Cederberg, C., Sonesson, U., Van Otterdijk, R., \& Meybeck, A. (2011). Global food losses and food waste (pp. 1-38). Rome: FAO.

Hald, K. S., \& Kinra, A. (2019). How the blockchain enables and constrains supply chain performance. International Journal of Physical Distribution and Logistics Management., 49(4), 376-397.

Hang, L., Ullah, I., \& Kim, D. H. (2020). A secure fish farm platform based on blockchain for agriculture data integrity. Computers and Electronics in Agriculture, 170, 105251.

Hughes, L., Dwivedi, Y. K., Misra, S. K., Rana, N. P., Raghavan, V., \& Akella, V. (2019). Blockchain research, practice and policy: Applications, benefits, limitations, emerging research themes and research agenda. International Journal of Information Management, 49, 114-129.

Iansiti, M., \& Lakhani, K. R. (2017). The truth about blockchain. Harvard Business Review, 95(1), 118-127.

Irani, Z., \& Sharif, A. M. (2016). Sustainable food security futures: Perspectives on food waste and information across the food supply chain. Journal of Enterprise Information Management, 29(2), 171-178.

Kamble, S. S., Gunasekaran, A., \& Sharma, R. (2020). Modeling the blockchain enabled traceability in agriculture supply chain. International Journal of Information Management, 52, 101967.

Kamilaris, A., Fonts, A., \& Prenafeta-Boldv́, F. X. (2019). The rise of blockchain technology in agriculture and food supply chains. Trends in Food Science \& Technology, 91, 640-652.

Kandasamy, W. V., Smarandache, F., \& Ilanthenral, K. (2007). Elementary fuzzy matrix theory and fuzzy models for social scientists. Infinite Study.

Kattumuri, R. (2011), "Food security and the targeted public distribution system in India", Working paper, Asia Research Centre, London School of Economics and Political Science, Vol. 38, London.

Kaur, H. (2021). Modelling internet of things driven sustainable food security system. Benchmarking: an International Journal, 28(5), 1740-1760.

Kaur, J., Sidhu, R., Awasthi, A., Chauhan, S., \& Goyal, S. (2018). A DEMATEL based approach for investigating barriers in green supply chain management in Canadian manufacturing firms. International Journal of Production Research, 56(1-2), 312-332.

Keskin, G. A. (2015). Using integrated fuzzy DEMATEL and fuzzy C: Means algorithm for supplier evaluation and selection. International Journal of Production Research, 53(12), 3586-3602.

Khandekar, M. L. (2013). Are extreme weather events on the rise? Energy and Environment, 24(3-4), 537-549.

Khurana, M. K., Mishra, P. K., Jain, R., \& Singh, A. R. (2010). Modeling of information sharing enablers for building trust in Indian manufacturing industry: An integrated ISM and fuzzy MICMAC approach. International Journal of Engineering Science and Technology, 2(6), 1651-1669.

Klerkx, L., \& Rose, D. (2020). Dealing with the game-changing technologies of Agriculture 4.0: How do we manage diversity and responsibility in food system transition pathways? Global Food Security, 24, 100347.

Krejci, C. C., \& Beamon, B. M. (2010). Environmentally-conscious supply chain design in support of food security. Operations and Supply Chain Management, 3(1), 14-29.

Kshetri, N. (2019). Blockchain and the Economics of Food Safety. IT Professional, 21(3), 63-66.

Kumar, A. (2021). Improvement of public distribution system efficiency applying blockchain technology during pandemic outbreak (COVID-19). Journal of Humanitarian Logistics and Supply Chain Management, 11(1), 1-28.

Kumar, A., Liu, R., \& Shan, Z. (2020). Is blockchain a silver bullet for supply chain management? Technical challenges and research opportunities. Decision Sciences, 51(1), 8-37.

Lamba, K., \& Singh, S. P. (2018). Modeling big data enablers for operations and supply chain management. The International Journal of Logistics Management, 29(2), 629-658.

Leng, K., Bi, Y., Jing, L., Fu, H. C., \& Van Nieuwenhuyse, I. (2018). Research on agricultural supply chain system with double chain architecture based on blockchain technology. Future Generation Computer Systems, 86, 641-649.

Li, Z., Wang, W. M., Liu, G., Liu, L., He, J., \& Huang, G. Q. (2018). Toward open manufacturing. Industrial Management and Data Systems, 118(1), 303-320.

Li, J., \& Wang, X. (2018, May). Research on the Application of Blockchain in the Traceability System of Agricultural Products. In 2018 2nd IEEE Advanced Information Management, Communicates, Electronic and Automation Control Conference (IMCEC) (pp. 2637-2640). IEEE.

Lin, R. J. (2013). Using fuzzy DEMATEL to evaluate the green supply chain management practices. Journal of Cleaner Production, 40, 32-39.

Lin, Y. P., Petway, J., Anthony, J., Mukhtar, H., Liao, S. W., Chou, C. F., \& Ho, Y. F. (2017). Blockchain: The evolutionary next step for ICT E-agriculture. Environments, 4(3), 50.

Lin, Q., Wang, H., Pei, X., \& Wang, J. (2019). Food safety traceability system based on blockchain and epcis. IEEE Access, 7, 20698-20707. 
Lobell, D. B., Burke, M. B., Tebaldi, C., Mastrandrea, M. D., Falcon, W. P., \& Naylor, R. L. (2008). Prioritizing climate change adaptation needs for food security in 2030. Science, 319(5863), 607-610.

Mahapatra, M. S., \& Mahanty, B. (2018). India's national food security programme: A strategic insight. Sādhanā, 43(12), 194.

Maharashtra to use blockchain technology in agriculture marketing, vehicle registration. (2019). https://tinyurl. com/4m93b6f8. Last accessed on 16/07/2021.

Mangla, S. K., Kumar, P., \& Barua, M. K. (2014). Flexible decision approach for analysing performance of sustainable supply chains under risks/uncertainty. Global Journal of Flexible Systems Management, 15(2), 113-130.

Mogale, D. G., Cheikhrouhou, N., \& Tiwari, M. K. (2020). Modelling of sustainable food grain supply chain distribution system: A bi-objective approach. International Journal of Production Research, 58(18), 5521-5544.

Narayanan, S. (2015). Food security in India: The imperative and its challenges. Asia and the Pacific Policy Studies, 2(1), 197-209.

NASSCOM (2019), Avasant India Blockchain Report 2019 Executive Summary. https://community.nasscom. in/download.php?file=wp-content/uploads/attachment/15216-executive-summary-avasant-nasscomblockchain-report-final.pdf. Accessed on February $22^{\text {nd }} 2021$.

Pathak, D. K., Thakur, L. S., \& Rahman, S. (2019). Performance evaluation framework for sustainable freight transportation systems. International Journal of Production Research, 57(19), 6202-6222.

Pearson, S., May, D., Leontidis, G., Swainson, M., Brewer, S., Bidaut, L., \& Zisman, A. (2019). Are Distributed Ledger Technologies the panacea for food traceability? Global Food Security, 20, 145-149.

Queiroz, M. M., \& Wamba, S. F. (2019). Blockchain adoption challenges in supply chain: An empirical investigation of the main drivers in India and the USA. International Journal of Information Management, 46, 70-82.

Raghuvanshi, R.S. (2008), "Crop insurance - a case for effective implementation of policies by India”, available at: https://ssrn.com/abstract=934491 (accessed on September 22nd 2019).

Ramakrishna, R., Subbarao, N., \& Chiranjeevi, C. (2012). Role of women in improving household food security in India. Indian Journal of Agricultural Economics, 67(3), 525.

Raut, R. D., Gardas, B. B., Kharat, M., \& Narkhede, B. (2018). Modeling the drivers of post-harvest losses-MCDM approach. Computers and Electronics in Agriculture, 154, 426-433.

Raut, R. D., Gardas, B. B., Narkhede, B. E., \& Jha, M. K. (2019). Analysing the challenges in sustainable agricultural supply chain system in India. International Journal of Business Excellence, 18(3), 336-359.

Raval, S. J., Kant, R., \& Shankar, R. (2018). Lean Six Sigma implementation: Modelling the interaction among the enablers. Production Planning and Control, 29(12), 1010-1029.

Ray, D. K., Ramankutty, N., Mueller, N. D., West, P. C., \& Foley, J. A. (2012). Recent patterns of crop yield growth and stagnation. Nature Communications, 3, 1293.

Saberi, S., Kouhizadeh, M., Sarkis, J., \& Shen, L. (2019). Blockchain technology and its relationships to sustainable supply chain management. International Journal of Production Research, 57(7), 2117-2135.

Sage, A. (1977). Interpretive structural modeling: methodology for large-scale systems. McGraw-Hill.

Salah, K., Nizamuddin, N., Jayaraman, R., \& Omar, M. (2019). Blockchain-based soybean traceability in agricultural supply chain. IEEE Access, 7, 73295-73305.

Sharma, R., Zhang, C., Wingreen, S. C., Kshetri, N., \& Zahid, A. (2019). Design of Blockchain-based Precision Health-Care using soft systems methodology. Industrial Management and Data Systems., 120(3), 608-632.

Si, S. L., You, X. Y., Liu, H. C., \& Zhang, P. (2018). DEMATEL technique: A systematic review of the stateof-the-art literature on methodologies and applications. Mathematical Problems in Engineering, 2018, 3696457. https://doi.org/10.1155/2018/3696457

Spices board inks deal with UNDP to develop blockchain-powered traceability interface. (2021). https:// tinyurl.com/kayy6n7w. Last accessed on 16/07/2021.

Srivastav, N., \& Dubey, A. (2004). How and why the access to public distribution system does not enhance the food security among the people of North-East India: an inter-state analysis. Available at SSRN 1816304.

Srivastava, S. K., Chaudhuri, A., \& Srivastava, R. K. (2015). Propagation of risks and their impact on performance in fresh food retail. The International Journal of Logistics Management, 26(3), 568-602.

Sushil, S. (2012). Interpreting the interpretive structural model. Global Journal of Flexible Systems Management, 13(2), 87-106.

Sushil. (2017). Multi-criteria valuation of flexibility initiatives using integrated TISM-IRP with a big data framework. Production Planning and Control, 28(11-12), 999-1010.

Sushil. (2018). How to check correctness of total interpretive structural models? Annals of Operations Research, 270(1-2), 473-487. 
Thakur, V., Doja, M. N., Dwivedi, Y. K., Ahmad, T., \& Khadanga, G. (2020). Land records on blockchain for implementation of land titling in India. International Journal of Information Management, 52, 101940.

Tian, F. (2017, June). "A supply chain traceability system for food safety based on HACCP, blockchain \& Internet of things". In Service Systems and Service Management (ICSSSM), 2017 International Conference on (pp. 1-6). IEEE.

Tian, Feng. "An agri-food supply chain traceability system for China based on RFID \& blockchain technology." In Service Systems and Service Management (ICSSSM), 2016 13th International Conference on, pp. 1-6. IEEE, 2016.

Timmer, M. P., Erumban, A. A., Los, B., Stehrer, R., \& De Vries, G. J. (2014). Slicing up global value chains. Journal of Economic Perspectives, 28(2), 99-118.

Villalobos, J. R., Soto-Silva, W. E., González-Araya, M. C., \& González-Ramirez, R. G. (2019). Research directions in technology development to support real-time decisions of fresh produce logistics: A review and research agenda. Computers and Electronics in Agriculture, 167, 105092.

Viswanadham, N., \& Kameshwaran, S. (2013). The supply chain ecosystem framework (pp. 17-44). World Scientific Book Chapters.

Wamba, S. F., \& Queiroz, M. M. (2020). Blockchain in the operations and supply chain management: Benefits, challenges and future research opportunities. International Journal of Information Management, 25, 102064

Wang, Y., Han, J. H., \& Beynon-Davies, P. (2019). Understanding blockchain technology for future supply chains: A systematic literature review and research agenda. Supply Chain Management: An International Journal, 24(1), 62-84.

Wheeler, T., \& Von Braun, J. (2013). Climate change impacts on global food security. Science, 341(6145), 508-513.

Yadav, V. S., Singh, A. R., Raut, R. D., \& Govindarajan, U. H. (2020). Blockchain technology adoption barriers in the Indian agricultural supply chain: an integrated approach. Resources, Conservation and Recycling, $161,104877$.

Yadav V. S., \& Singh A. R., (2019a), "A Systematic Literature Review of Blockchain Technology in Agriculture", Proceedings of the International Conference on Industrial Engineering and Operations Management Pilsen, Czech Republic, 973-981.

Yadav, V. S., \& Singh, A. R. (2019b). "Use of blockchain to solve select issues of Indian farmers". In AIP Conference Proceedings (Vol. 2148, No. 1, p. 030050). AIP Publishing.

Ying, W., Jia, S., \& Du, W. (2018). Digital enablement of blockchain: Evidence from HNA group. International Journal of Information Management, 39, 1-4.

Zhao, G., Liu, S., Lopez, C., Lu, H., Elgueta, S., Chen, H., \& Boshkoska, B. M. (2019). Blockchain technology in agri-food value chain management: A synthesis of applications, challenges and future research directions. Computers in Industry, 109, 83-99.

Zheng, Z., Xie, S., Dai, H. N., Chen, X., \& Wang, H. (2018). Blockchain challenges and opportunities: A survey. International Journal of Web and Grid Services, 14(4), 352-375.

Zheng, K., Zhang, Z., \& Gauthier, J. (2020). Blockchain-based intelligent contract for factoring business in supply chains. Annals of Operations Research. https://doi.org/10.1007/s10479-020-03601-z

Publisher's Note Springer Nature remains neutral with regard to jurisdictional claims in published maps and institutional affiliations. 